\title{
Structure of Strontium Aluminosilicate Glasses from Molecular Dynamics Simulations, Neutron Diffraction and Nuclear Magnetic Resonance Studies
}

Thibault Charpentier $^{1}{ }^{*}$, Kirill Okhotnikov ${ }^{1}$, Alexey N. Novikov ${ }^{2}$, Louis Hennet ${ }^{2}$, Henry E. Fischer $^{3}$, Daniel R. Neuville ${ }^{4}$, Pierre Florian ${ }^{2}$

1. NIMBE, CEA, CNRS, Université Paris-Saclay, CEA Saclay, 91191 Gif-sur-Yvette cedex, France.

2. CEMHTI UPR3079 CNRS, Univ. Orléans, F-45071 Orléans, France

3. Institut Laue-Langevin, 38042 Grenoble Cedex 9, France

4. IPGP UMR7154 CNRS, Géomatériaux, Paris Sorbonne Cité, 75005 Paris, France

* thibault.charpentier@cea.fr

\section{Abstract}

The structure of strontium glasses with composition $\left(\mathrm{SiO}_{2}\right)_{1-2 x}\left(\mathrm{Al}_{2} \mathrm{O}_{3}\right)_{x}(\mathrm{SrO})_{x}$ $\left(\mathrm{R}=[\mathrm{SrO}] /\left[\mathrm{Al}_{2} \mathrm{O}_{3}\right]=1\right)$ and $\left(\mathrm{SiO}_{2}\right)_{1-4 x}\left(\mathrm{Al}_{2} \mathrm{O}_{3}\right)_{x}(\mathrm{SrO})_{3 \times}(\mathrm{R}=3)$ have been explored experimentally over both short and intermediate length scales using neutron diffraction, ${ }^{27} \mathrm{Al}$ and ${ }^{29} \mathrm{Si}$ nuclear magnetic resonance and classical molecular dynamics simulations in model systems containing around 10000 atoms. We aim at understanding the structural role of aluminum and strontium as a function of the chemical composition of these glasses. Short- and medium-range structure such as aluminum coordination, bond angle distribution, $\mathrm{Q}^{(\mathrm{n})}$ distribution and oxygen speciation have been systematically studied. Two potential forms of the repulsive short-range interactions have been investigated, namely the Buckingham and Morse forms. The comparison allows us to derive general trends independent of the particular choice of the potential form. In both cases, it is found that aluminum ions are mainly four-fold coordinated and mix with the silicon network favoring $\mathrm{Al} / \mathrm{Si}$ mixing in terms of Al-O-Si linkages. For the $\mathrm{R}=1$ glass series, despite the full charge compensation ([SrO] $\left.=\left[\mathrm{Al}_{2} \mathrm{O}_{3}\right]\right)$, a small fraction of five-fold aluminum is observed both experimentally and in MD simulations, while the concentration of six-fold aluminum is negligible. MD shows that 
five-fold aluminum units $\mathrm{AlO}_{5}$ preferentially adopt small rings configuration and link to tricoordinated oxygen atoms which population increases with the aluminum content and are mainly found in $\mathrm{OAl}_{3}$ and $\mathrm{OAl}_{2} \mathrm{Si}$ configurations. The modeled $\mathrm{Sr}$ speciation mainly involves $\mathrm{SrO}_{7}$ and $\mathrm{SrO}_{8}$ polyhedra, giving a range of average $\mathrm{Sr}^{2+}$ coordination numbers between 7 and 8 slightly dependent on the short-range repulsive potential form. A detailed statistical analysis of the $\mathrm{T}-\mathrm{O}-\mathrm{T}^{\prime}\left(\mathrm{T}, \mathrm{T}^{\prime}=\mathrm{Al}, \mathrm{Si}\right)$, accounting for the population of the various oxygen speciation, reveals that both potentials predicts a nearly identical $\mathrm{Al} / \mathrm{Si}$ mixing.

\section{Introduction}

Thanks to their good mechanical and high chemical durability, aluminosilicate glasses have found wide industrial and technological applications. In these respects and also because of their importance in geoscience due to their presence in the Earth's magma, alkali-earth aluminosilicate have been experimentally and computationally thoroughly investigated, but almost exclusively with $\mathrm{Ca}^{++}$cations (CAS system), see for example Refs. ${ }^{1-10}$ where the fully charge balanced tectosilicate join has been the most studied. Despite the full charge compensation, intrinsic defects such as non-bridging oxygens ${ }^{1,11-14}$ or higher coordinated states of aluminium $\left(\mathrm{AlO}_{5,6}\right)^{10,12,15}$ that can be directly observed and easily quantified from ${ }^{27} \mathrm{Al} N \mathrm{NMR}$, are observed. In order to explain compensation of the excess of charge, tricoordinated oxygens (also referred to as tricluster oxygens or triply-bonded oxygens) have also been invoked ${ }^{8,16,17}$ but their existence is still mainly supported by MD simulations $s^{4,8,18-20}$ only. Indeed quantum chemical studies have shown that such species could not be resolved by ${ }^{17} \mathrm{O}$ NMR spectroscopy. ${ }^{21-23}$

Conversely to CAS, the structure of strontium aluminosilicate glasses (SAS) have been only scarcely studied, despite their high potential for developing new materials, such a 
transparent ceramics, ${ }^{24,25}$ high temperature sealants ${ }^{26}$ and refractory materials. ${ }^{27,28}$ RMC studies of the glass $\mathrm{SrO}-\mathrm{Al}_{2} \mathrm{O}_{3}-4 \mathrm{SiO}_{2}{ }^{29}$ suggested a non-homogenous spatial distribution of $\mathrm{Sr}$ atoms with a Sr-O distance which is longer in aluminosilicate $(2.7 \AA)$ that in binary silicate $(2.55 \AA ̊)$ glasses, in agreement with analogous crystal structures $\mathrm{SrAl}_{2} \mathrm{Si}_{2} \mathrm{O}_{8}$ and $\mathrm{SrSiO}_{3}$. This pointed out the dominant role of $\mathrm{Sr}$ as charge compensator in $\mathrm{SAS}$ on the $\left[\mathrm{Al}_{2} \mathrm{O}_{3}=\mathrm{SrO}\right.$ ] join ( $\mathrm{R}$ = 1). X-ray analysis in borosilicate glasses showed an average Sr-O distance of $2.53 \AA$ with coordination number ranging from 4 to $6 .{ }^{30}$ More recently, ${ }^{31}$ a systematic study of the $R=1$ glass compositions showed that $\mathrm{Al}$ is predominantly in tetrahedral form, with a maximum of $5 \%$ in fivefold coordinated units. Strontium coordination number was found to be around 9 (from Sr K-edge XAS).

Thus, including strontium in a more systematic way is of interest to complete the aluminosilicate glass structure frame. This will also complete a recent attempt to rationalize the effect of the cation field strength on the appearance of high coordination $\mathrm{AlO}_{5,6}$ sites, ${ }^{32}$ even at exact charge balance condition. Generally, it was observed that the tendency of the modifier cations to charge balance $\mathrm{AlO}_{4}$ units has decreasing probability with increasing ionic field strength as higher field strength often promotes the appearance of negative charge such as non-bridging oxygens or highly-charged Al-O-Al groups. ${ }^{33}$ The exact role of high coordination states of aluminum to the global charge balance, often accompanied by the appearance of tricoordinated oxygens (denoted $\mathrm{O}^{[3]}$ ) and/or non-bridging oxygens (denoted $\left.\mathrm{O}^{[1]}\right)$, still need to be clarified. This highlights the three mechanisms that have been proposed for local charge compensations in aluminosilicate glasses. The first one is the formation of highly coordinated aluminums such as $\mathrm{AlO}_{5}$ and $\mathrm{AlO}_{6}$. The second mechanism postulates the idea of tricoordinated oxygens (also referred to as triclusters or triply bonded oxygens), involving the sharing of oxygen among three network forming units $\left(\mathrm{SiO}_{4}, \mathrm{AlO}_{4}\right.$ but also 
$\left.\mathrm{AlO}_{5}\right)$, as corroborated directly by many MD studies and indirectly by NMR studies. The third one relies on the formation of (non-stoichiometric) non-bridging oxygens which have been observed in potassium, calcium and barium aluminosilicates but in amounts decoupled from the concentration of $\mathrm{AlO}_{5}$ species. ${ }^{34}$ In addition, it has been shown recently experimentally that the speculated $\mathrm{Al}-\mathrm{O}^{[1]}$ bonds also form in rare-earth aluminosilicate glasses. ${ }^{35,36}$

In this work, two strontium aluminosilicate glass series are examined: the first is on the exact charge compensation line $\left([\mathrm{SrO}] /\left[\mathrm{Al}_{2} \mathrm{O}_{3}\right]=1\right)$ with compositions $\left(\mathrm{SiO}_{2}\right)_{1}$ ${ }_{2 x}\left(\mathrm{Al}_{2} \mathrm{O}_{3}\right)_{x}(\mathrm{SrO})_{x}$; in the second, strontium oxide is in excess $\left((\mathrm{SrO}] /\left[\mathrm{Al}_{2} \mathrm{O}_{3}\right]=3\right)$ with compositions $\left(\mathrm{SiO}_{2}\right)_{1-4 x}\left(\mathrm{Al}_{2} \mathrm{O}_{3}\right)_{x}(\mathrm{SrO})_{3 x}$. These glasses are investigated theoretically by means of molecular dynamics simulations using two forms of potential models made by two-body interactions. Although these potential sets predict reasonable glass structures with respect to the neutron diffraction and nuclear magnetic resonance data, both featuring an increasing concentration of both high coordination aluminum units $\mathrm{AlO}_{5,6}$, tricoordinated and non-bridging oxygen atoms with the aluminum content, they are found to differ mainly in the relative populations of the various oxygen species $O^{[n]}(n=1-3)$ whereas $\mathrm{Sr}$ coordination numbers and $\mathrm{Al} / \mathrm{Si}$ mixing are similar. This first allows us to draw some general conclusions about the role of the interaction potential sets. Secondly, we determine the intimate relationships that exists between the two main charge compensation mechanisms: high coordinated aluminum units and $\mathrm{O}^{[1],[3]}$ oxygens.

\section{Materials and Methods}

2.1 Starting Materials. Strontium aluminosilicate samples were made by a traditional meltquenching procedure and characterized (composition, homogeneity, density) as described in ref $^{31}$ for the $R=1$ glass series. For glass samples that could not be obtained using this 
procedure (SA50.25 and SA75.12), small glass spheres were prepared employing an aerodynamics levitation device coupled to two $\mathrm{CO}_{2}$ lasers. ${ }^{37}$ Glasses are named SAxx.yy where $x x$ and yy are the $\mathrm{SiO}_{2}$ and $\mathrm{Al}_{2} \mathrm{O}_{3}$ content in mol\%, respectively.

2.2 Nuclear Magnetic Resonance. ${ }^{27}$ AI MAS NMR spectra have been collected on a Avance III Bruker $850 \mathrm{MHz}$ (20.0T) spectrometer operating at a Larmor frequency of $195.5 \mathrm{MHz}$ and using a $2.5 \mathrm{~mm}$ Bruker CPMAS probe at a spinning frequency of $30 \mathrm{kHz}$. A short single pulse excitation of 0.4 us, i.e. less than $\pi / 18$, was used to ensure quantitativeness (i.e., in order to avoid non-homogeneous excitation of the line because of dependence of the excitation efficiency upon quadrupolar interaction for long pulse length) for with a recycle delay of 0.15 s. Triple Quantum MQMAS spectra were acquired using a shifted Echo pulse sequence. ${ }^{38}$ Chemical shifts are referenced to a $1 \mathrm{M}$ aqueous $\mathrm{Al}\left(\mathrm{NO}_{3}\right)_{3}$ solution.

${ }^{29} \mathrm{Si}$ MAS NMR spectra have been collected on a Avance I Bruker $300 \mathrm{MHz}$ (7.05T) spectrometer operating at a Larmor frequency of $59.5 \mathrm{MHz}$ and using a $4 \mathrm{~mm}$ Bruker CPMAS at a spinning frequency of $10 \mathrm{kHz}$. Data were acquired a CPMG pulse sequence ${ }^{39-41}$ with a recycle delay of 200s and typically 256 scans. 16 echoes with an echo delay of 6 ms between consecutive $180^{\circ}$ pulses were accumulated. They were then summed up and Fourier transformed to obtain the spectra. The spectra are referenced to an external tetrakis(trimethylsilyl)silane (TKS) sample, for which the highest intensity peak was positioned at $-9.9 \mathrm{ppm}$ from that of TMS.

All data were processed and fitted using an in-house written software (T. Charpentier), including shortest-path analysis for the search of primary rings.

2.3 Neutron diffraction. The neutron diffraction measurements were carried out on the D4C diffractometer $^{42}$ at the Institute Laue Langevin (ILL) in Grenoble (France). A neutron 
wavelength $(\lambda)$ of $0.4985 \AA$ was selected for the measurements. Glass samples ( 3 to $4 \mathrm{~mm}$ in diameter) were placed into a vacuum chamber that was pumped down to a pressure of $10^{-4}$ mbar. The total duration of each run was about 3 hours, including the displacement of the detector.

The procedure for the data treatment is described in details in ref. ${ }^{43}$ The structure factors were obtained using the program CORRECT $^{44}$ which corrects the data for attenuation, background, multiple scattering and inelasticity (Placzek) effects. Finally, the total pair distribution functions were then calculated from the structure factors by the Fourier transform:

$$
G(r)-1=\frac{1}{2 \pi^{2} r \rho_{0}} \int_{0}^{\infty}[S(Q)-1] Q \sin (Q r) d Q
$$

where $\boldsymbol{\rho}_{\mathbf{0}}$ denotes the atomic number density. The later is calculated using densities measured with the Archimedean method applying toluene as immersion liquid.

2.4 Molecular Dynamics Simulations. A single model for each composition was generated as described in Table 1. MD simulations were performed with the DL_POLY program. ${ }^{45,46}$ Two pairwise potential models were compared; both includes the long range Coulombic contributions with partial-charge rigid-ion model. In the first set, short range interactions were chosen in the Buckingham form:

$$
V(r)=A_{i j} \exp \left(-r / \rho_{i j}\right)-C_{i j} /_{r^{6}}
$$

In the second set, a Morse function was chosen including a repulsion term $C / r^{12}$ as:

$$
V(r)=D_{i j}\left[\left\{1-e^{-a_{i j}\left(r-r_{0}\right)}\right\}^{2}-1\right]-C_{i j} / r^{12}
$$

Parameters $A_{i j}, \rho_{i j}, C_{i j}, D_{i j}, a_{i j}$ and $r_{0}$ are given in Table 2 and Table 3. Morse parameters were developed by Pedone et al. ${ }^{47}$ and Buckingham ones are from previous studies, ${ }^{48-50}$ 
except for Sr-O interaction for which new parameters were derived as described by fitting DFT calculations ${ }^{51}$ as described in the Supporting Information. Buckingham potential sets were corrected at very short range as described in Ref. ${ }^{51}$

Coulombic interactions were calculated using the Ewald Sum summation method with a precision of $10^{-6}$, a real-space cutoff of $9 \AA$ to evaluate repulsive forces with periodic boundary conditions and $12 \AA$ for the Coulombic interactions. A time step of $0.5 \mathrm{fs}$ was used. The Melt and Quench method was employed to generate the glass structures. Starting from random initial structures (generated with shortest bond length constraints between atom pairs), they were melted during $100 \mathrm{ps}$ at $3500 \mathrm{~K}$ to remove memory effects and then cooled subsequently to $300 \mathrm{~K}$ in steps of $100 \mathrm{~K}$. At each temperature, a 50 ps relaxation was allowed in the NVT ensemble (using a Berendsen thermostat with a 1 ps relaxation time constant) followed by 50ps in the NVE ensemble. This annealing protocol leads to a nominal quenching rate of $1 \mathrm{~K} / \mathrm{ps}$.

Data collection was performed every 20 steps during the last 50000 steps of an extended 200 ps MD run in the NVE ensemble at $300 \mathrm{~K}$. Data were processed and analyzed with an inhouse written code (T. Charpentier). Coordination numbers were calculated using cutoff radius values of $2.2 \AA$ for $\mathrm{Si}-\mathrm{O}$ and $\mathrm{Al}-\mathrm{O}$, and $3.5 \AA$ for $\mathrm{Sr}-\mathrm{O}$, as determined from the minimum after the first peak maximum of the partial radial distribution function.

Table 1. Compositions, Densities and Simulation Cell Information of the Simulated Glasses

\begin{tabular}{|c|c|c|c|c|c|c|}
\hline \multirow{2}{*}{ Glass } & \multicolumn{4}{|c|}{ Number of atoms } & \multirow{2}{*}{$\begin{array}{l}\text { Density } \\
\left(\mathrm{g} / \mathrm{cm}^{3}\right)\end{array}$} & \multirow{2}{*}{$\begin{array}{c}\text { Edge } \\
\text { length }(\AA)\end{array}$} \\
\hline & $\mathrm{Al}$ & $\mathrm{O}$ & $\mathrm{Si}$ & $\mathrm{Sr}$ & & \\
\hline \multicolumn{7}{|c|}{$\mathrm{R}=1$} \\
\hline SA26.37 & 2160 & 5856 & 768 & 1080 & 3.298 & 51.3024 \\
\hline SA33.33 & 1968 & 5904 & 984 & 984 & 3.211 & 51.3232 \\
\hline SA42.29 & 1800 & 6200 & 1300 & 900 & 3.132 & 51.8642 \\
\hline SA50.25 & 1600 & 6400 & 1600 & 800 & 3.021 & 52.3286 \\
\hline SA57.21 & 1400 & 6500 & 1850 & 700 & 2.928 & 52.4819 \\
\hline
\end{tabular}




\begin{tabular}{|l|l|l|l|l|l|l|}
\hline SA63.18 & 1200 & 6500 & 2050 & 600 & 2.837 & 52.4319 \\
\hline SA75.12 & 800 & 6575 & 2475 & 425 & 2.636 & 52.7898 \\
\hline \multicolumn{7}{|l|}{} \\
\hline SA33.17 & 1200 & 5925 & 1175 & 1175 & 3.628 & 52.4750 \\
\hline SA42.14 & 1008 & 6120 & 1512 & 1584 & 3.482 & 52.6690 \\
\hline SA50.12 & 850 & 6175 & 1775 & 1350 & 3.349 & 52.3816 \\
\hline SA60.10 & 728 & 6552 & 2184 & 1092 & 3.139 & 52.9982 \\
\hline
\end{tabular}

Table 2. Parameters of the Buckingham Potentials

\begin{tabular}{|c|c|c|c|c|}
\hline Pair & $A(\mathrm{eV})$ & $\varrho(\AA)$ & $C\left(\mathrm{eV} . \AA^{6}\right)$ & Ref \\
\cline { 1 - 4 } $\mathrm{Al}^{+1.8}-\mathrm{O}^{-1.2}$ & 12201.417 & 0.195628 & 31.997 & \multirow{2}{*}{$(\mathrm{Du}, 2009)$} \\
\cline { 1 - 4 } $\mathrm{O}^{-1.2}-\mathrm{O}^{-12}$ & 1844.7458 & 0.343645 & 192.58 & \\
\cline { 1 - 3 } $\mathrm{Si}^{+2.4}-\mathrm{O}^{-12}$ & 13702.905 & 0.193817 & 54.681 & \\
\hline $\mathrm{Sr}^{+1.2}-\mathrm{O}^{-1.2}$ & 4314.907 & 0.312116 & 377.478 & This work \\
\hline
\end{tabular}

Table 3. Parameters of the Morse Potentials from ref 47

\begin{tabular}{|c|c|c|c|c|}
\hline Pair & $D(\mathrm{eV})$ & $\mathrm{a}(\AA)$ & $r_{0}\left(\AA^{2}\right)$ & $C\left(\mathrm{eV} . \AA^{12}\right)$ \\
\hline $\mathrm{Al}^{+1.8}-\mathrm{O}^{-1.2}$ & 0.361581 & 1.900442 & 2.164818 & 0.9 \\
\hline $\mathrm{O}^{-1.2}-\mathrm{O}^{-12}$ & 0.042395 & 1.379316 & 3.618701 & 22.0 \\
\hline $\mathrm{Si}^{+2.4}-\mathrm{O}^{-12}$ & 0.340554 & 2.0067 & 2.1 & 1.0 \\
\hline $\mathrm{Sr}^{+1.2}-\mathrm{O}^{-1.2}$ & 0.019623 & 1.886 & 3.32833 & 3.0 \\
\hline
\end{tabular}

\section{Results and Discussion}

3.1 Nuclear Magnetic Resonance Spectroscopy. ${ }^{27}$ Al MAS NMR spectra of the R=1 glass series have been recently reported ${ }^{31}$ but for the sake of completeness they will be shown here as well, along with the $\mathrm{R}=3$ glass series spectra; MQMAS spectra for both glass series detailed are given in the Supporting Information. Moreover although previous ${ }^{31}$ and present studies use the same model to simulate the same one-dimensional data set, the simulation procedure used here is slightly different as it relies on the MQMAS experiments as well and gives therefore an evaluation of the uncertainties in determining the NMR parameters.

In Figure 1 are shown the ${ }^{27}$ Al MAS NMR spectra, the variations of the mean isotropic chemical shift $\delta_{\text {iso }}$ and mean quadrupolar coupling constant $C_{Q}$ against the glass composition. The mean values of the NMR parameters were calculated from the NMR parameters distribution extracted from the MAS using constraints from the MQMAS spectra, 
as detailed in the Supporting Information. Note that for the SA63.18 glass, a small impurity is seen at about $10 \mathrm{ppm}\left(\alpha-\mathrm{Al}_{2} \mathrm{O}_{3}\right)$.

If for both glass series, $\mathrm{R}=1$ and $\mathrm{R}=3$, a dominant $\mathrm{AlO}_{4}$ speciation is clearly observed, a small amount of $\mathrm{AlO}_{5}$, ranging from 1 to $6 \%$ (Figure 2) is clearly revealed by MQMAS spectroscopy (see spectra in Supporting Information). This is quite surprising for the $R=3$ series as it could have been anticipated that the higher SrO concentration would have facilitated a full charge compensation of $\mathrm{AlO}_{4}$ units.

Concerning the dominant $\mathrm{AlO}_{4}$ units, both glass series exhibit a clear decrease of the isotropic chemical shift $\delta_{\text {iso }}$ against the ratio $\mathrm{r}=\mathrm{Si} / \mathrm{Al}$ with similar averaged slopes (see dashed line in Figure 1, right panel) of about $-4.8 \mathrm{ppm} / \mathrm{Si}$ and $-4.9 \mathrm{ppm} / \mathrm{Si}$ for $\mathrm{R}=1$ and $\mathrm{R}=3$, respectively. This variation can be safely ascribed to $\mathrm{Al} / \mathrm{Si}$ mixing: larger (resp. smaller) $\delta_{\text {iso }}$ corresponds to higher connectivity with aluminum (resp. silicon), as already observed and quantified in gehlenite. ${ }^{52}$ Such values of the slope are in good agreement with previously predicted values between -3 to $-5 \mathrm{ppm}$ in aluminosilicate glasses ${ }^{6}$ and experimentally observed value of $-3 \mathrm{ppm}$ in gehlenite. ${ }^{52}$ The ${ }^{27} \mathrm{Al}$ quadrupolar coupling constant $C_{Q}$ values vary in two steps: values first decrease for low silica content $(<40 \%)$ to reach in a second step a plateau for silica-rich compositions. For low silica content, higher Al-O-Al connectivity requires a larger amount of charge compensators in the surrounding of $\mathrm{Al}$ atoms which results in a larger local electric field gradient (EFG), thus larger $C_{Q}$. The origin of the overall reduction of $C_{Q}$ values from the $\mathrm{R}=1$ to $\mathrm{R}=3$ glass compositions is less clear. The presence of a higher amount of non-bridging oxygen atoms could help aluminum atoms in the system to adopt less distorted environments because of diminished constraints arising from reduced bonding with neighboring units (more depolymerized network). Further discussion regarding 
these aspects will be presented in a forthcoming paper combining present MD simulations with DFT-NMR calculations, using the methodology presented in Ref. ${ }^{6}$

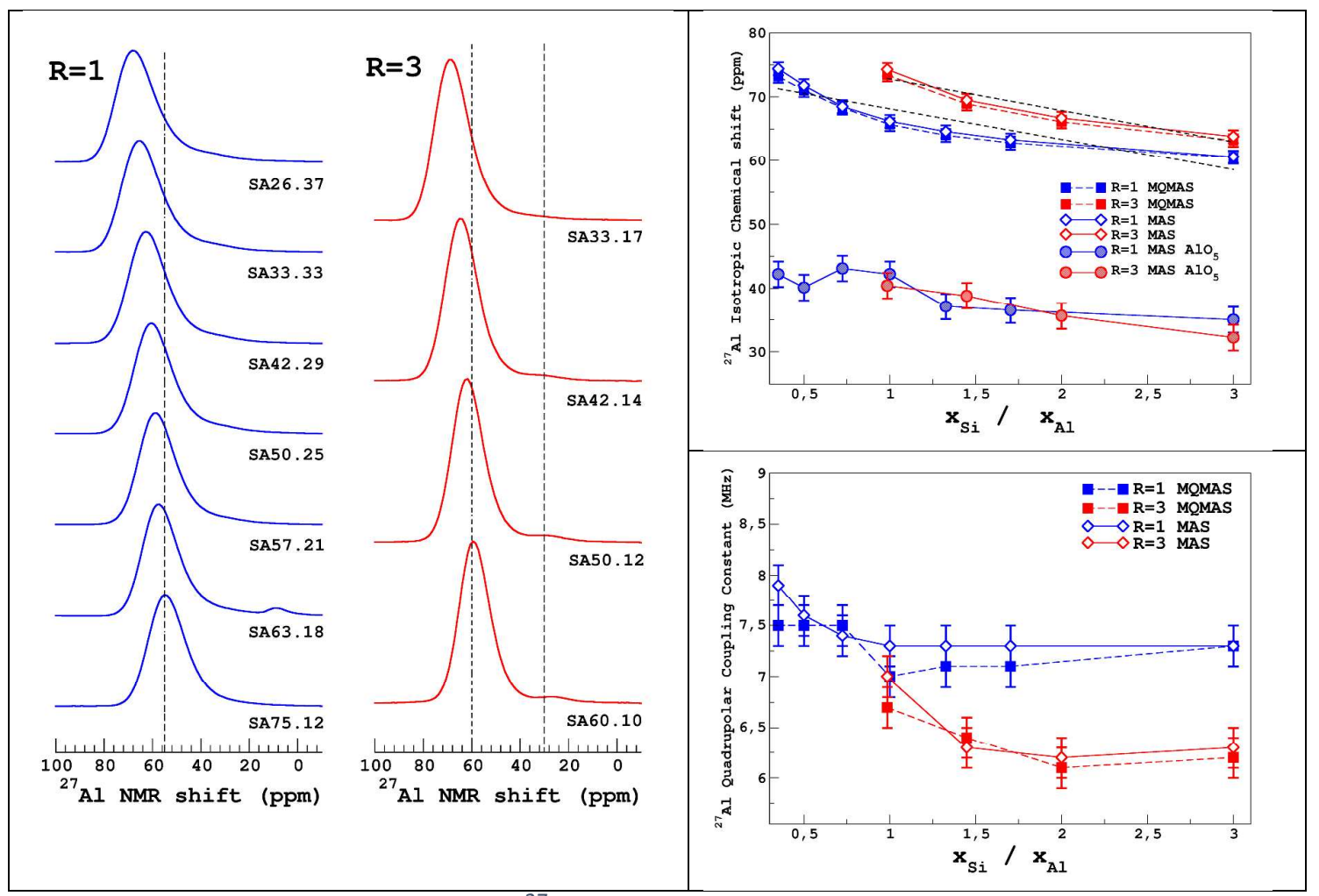

Figure 1. Left Panel: Experimental ${ }^{27}$ Al MAS NMR spectra of the strontium aluminosilicate glasses. Right panel: Variation of the mean isotropic chemical shift (top) and quadrupolar coupling constant (bottom) values against the glass composition, for $\mathrm{AlO}_{4}$ (and $\mathrm{AlO}_{5}$ groups for isotropic chemical shift values only). Values obtained from the analysis of MAS and MQMAS spectra are compared. See Supporting Information for details.

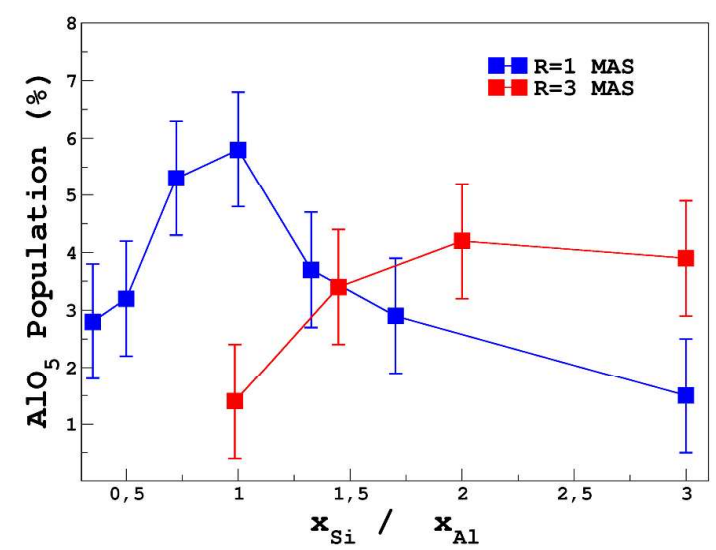

Figure 2. Variation of $\mathrm{AlO}_{5}$ population against the glass composition. 
Figure 3 shows the ${ }^{29}$ Si MAS NMR spectra, the variations of the mean isotopic chemical shift $\delta_{\text {iso }}$ (i.e., center of gravity) and widths of the spectra; dashed lines represent linear regression of $\delta_{i s o}$ values on specific ranges of composition (see below). For both glass series, increase of silica content yields a decrease of the isotropic chemical shift and increase of the spectrum's width. In the $\mathrm{R}=1$ glass series, according to previous studies of aluminosilicate glasses, $^{9,53-55}$ the variation of $\delta_{\text {iso }}$ can be interpreted in terms of the Si/Al mixing. It has been generally observed that one substitution of one bonded silicon for an aluminum leads to shift between +3 and $+5 \mathrm{ppm}$, in qualitative agreement with the observed slope of $2.1 \pm 0.3$ ppm/Al for the second part (for $x_{A l} / x_{S i}>1.5$, i.e, SA50.25, SA57.21, SA63.18 and SA75.12) whereas the first part (for $x_{A l} / x_{S i}<1.5$, i.e, SA26.37, SA33.33 and SA42.29)shows a slope of $12 \pm 3 \mathrm{ppm} /$ Al. This value approaches the $\mathrm{R}=3$ glass series ones, with a higher slope for the increase of $\delta_{\text {iso }}, 18 \pm 3 \mathrm{ppm} / \mathrm{Al}$, which is clearly indicative of the contribution of two mechanisms : Al/Si mixing and decrease of the amount of non-bridging oxygens $\mathrm{O}^{[1]}$. Each aluminum is coming with $1.5 \mathrm{Sr}^{2+}$ : the difference between the slopes, about $6 \mathrm{ppm} / \mathrm{Al}$, can be ascribed to the effect of one added NBO in the case $\mathrm{R}=3$. The residual of about $12 \mathrm{ppm} / \mathrm{Al}$ suggests that other mechanisms exist; MD can help understanding them.

In addition to the variation of $\delta_{i s o}$, both glass series show a significant increase of the spectra's widths against the silica content but with a similar slope. At first glance, this would suggest an increased local disorder around $\mathrm{SiO}_{4}$ units for lower aluminum and strontium content. However, recent investigations of the dependence of the ${ }^{29} \mathrm{Si}$ isotropic chemicals shift with the bond angle in tetrahedral linkages have shown that, depending on their connectivity, $\mathrm{Q}^{(\mathrm{n})}$ units may exhibit a different slope in their correlation between $\delta_{\text {iso }}$ and the average bond angle ${ }^{56}$. In other words, $\mathrm{Q}^{(\mathrm{n})}$ units have a different NMR response to the local disorder so that they may be characterized by a different linewidth even for a similar bond- 
angle distribution (BAD) around each environment. Such an effect will be investigated in a future work combining the present MD simulation with DFT-NMR calculations.

In conclusion, NMR clearly shows that tetrahedral coordination dominates the $\mathrm{AlO}_{\mathrm{p}}$ speciations for all the glass compositions investigated and continuous and smooth $\mathrm{Al} / \mathrm{Si}$ mixing occurs, as evidenced by the variations of the $\mathrm{NMR}$ parameters with the $\mathrm{SiO}_{2}$ content. Additionally, the presence of a small amount of $\mathrm{AlO}_{5}$ for all glass compositions suggest the presence of tricoordinated oxygens $\mathrm{O}^{[3]}$ involved in the local charge balance, even for the $\mathrm{R}=$ 3 glass series.

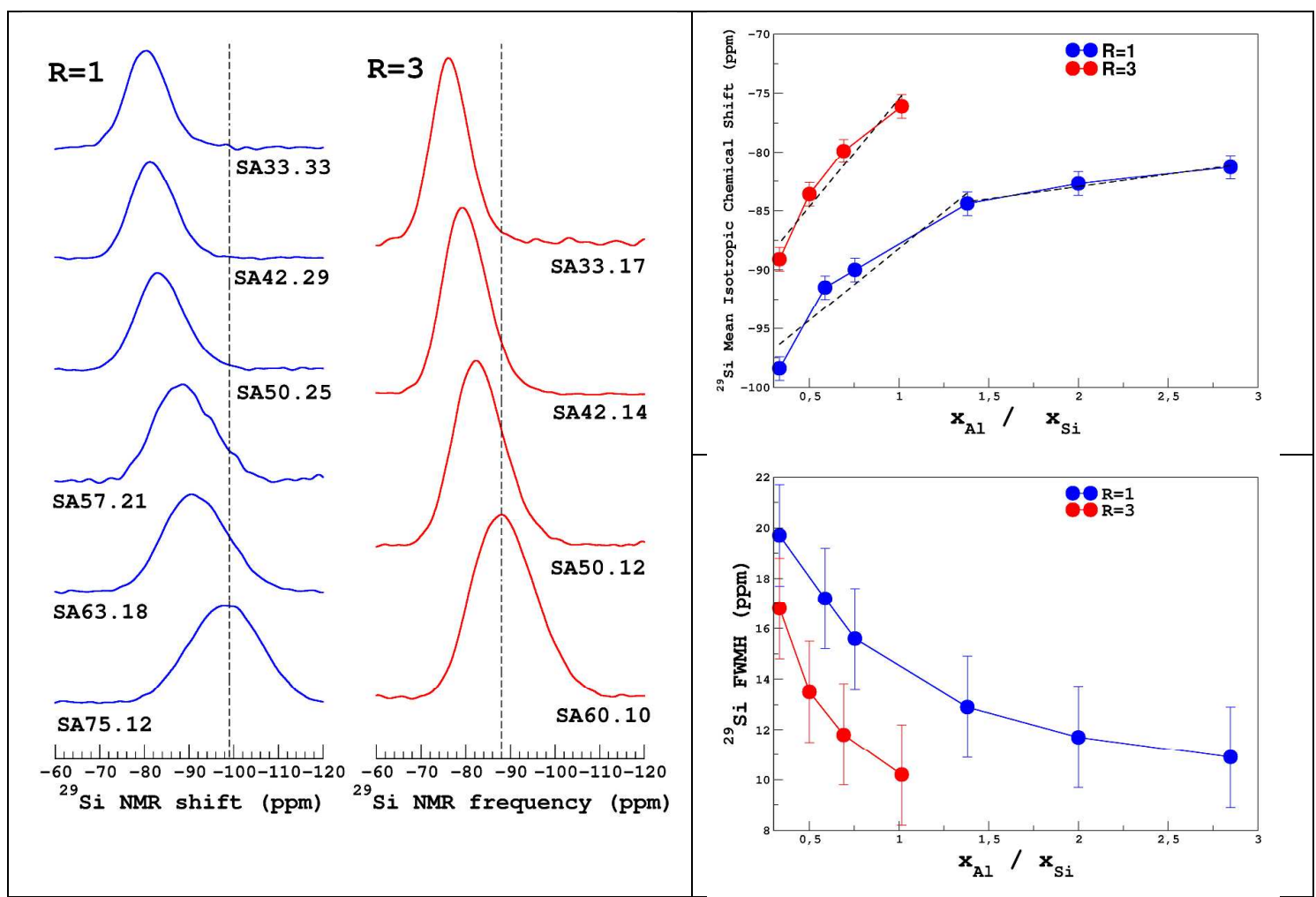

Figure 3. Left panel: Experimental ${ }^{29}$ Si MAS NMR spectra of the strontium aluminosilicate glasses. Right panel: variation of the (mean) isotropic chemical shift (center of gravity, top) and the spectral width (full width at middle height, FWMH, bottom) against the glass composition.

3.2 Neutron Diffraction and Molecular Dynamics Simulations. Our glasses have been further characterized using neutron diffraction. Experimental data in reciprocal space could be well 
reproduced by our MD simulations with the both potential models investigated in this work, as shown in the Supporting Information. Total structure factors were computed from partial structure factors using the standard approach based on the partial radial distribution function. $^{2}$
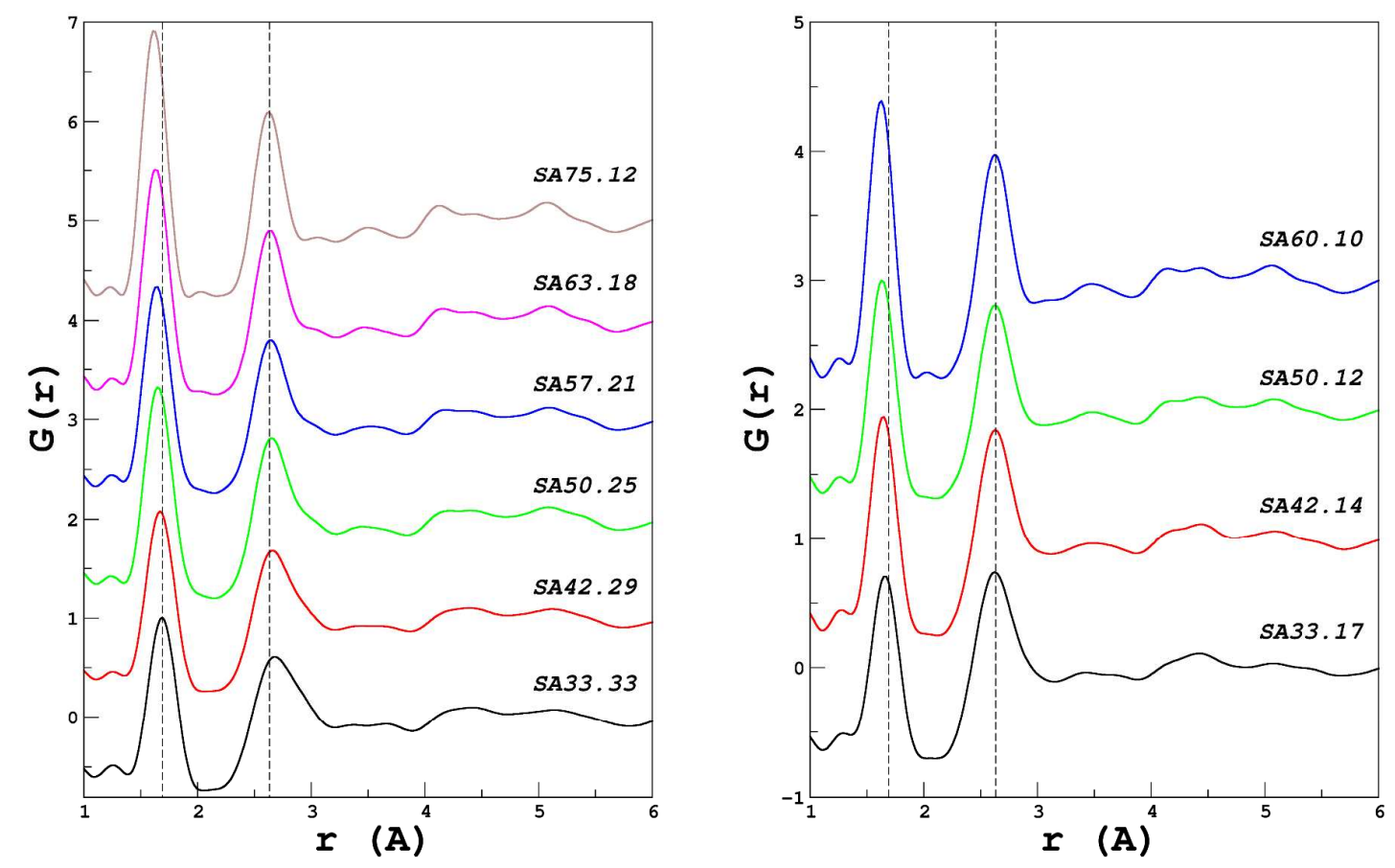

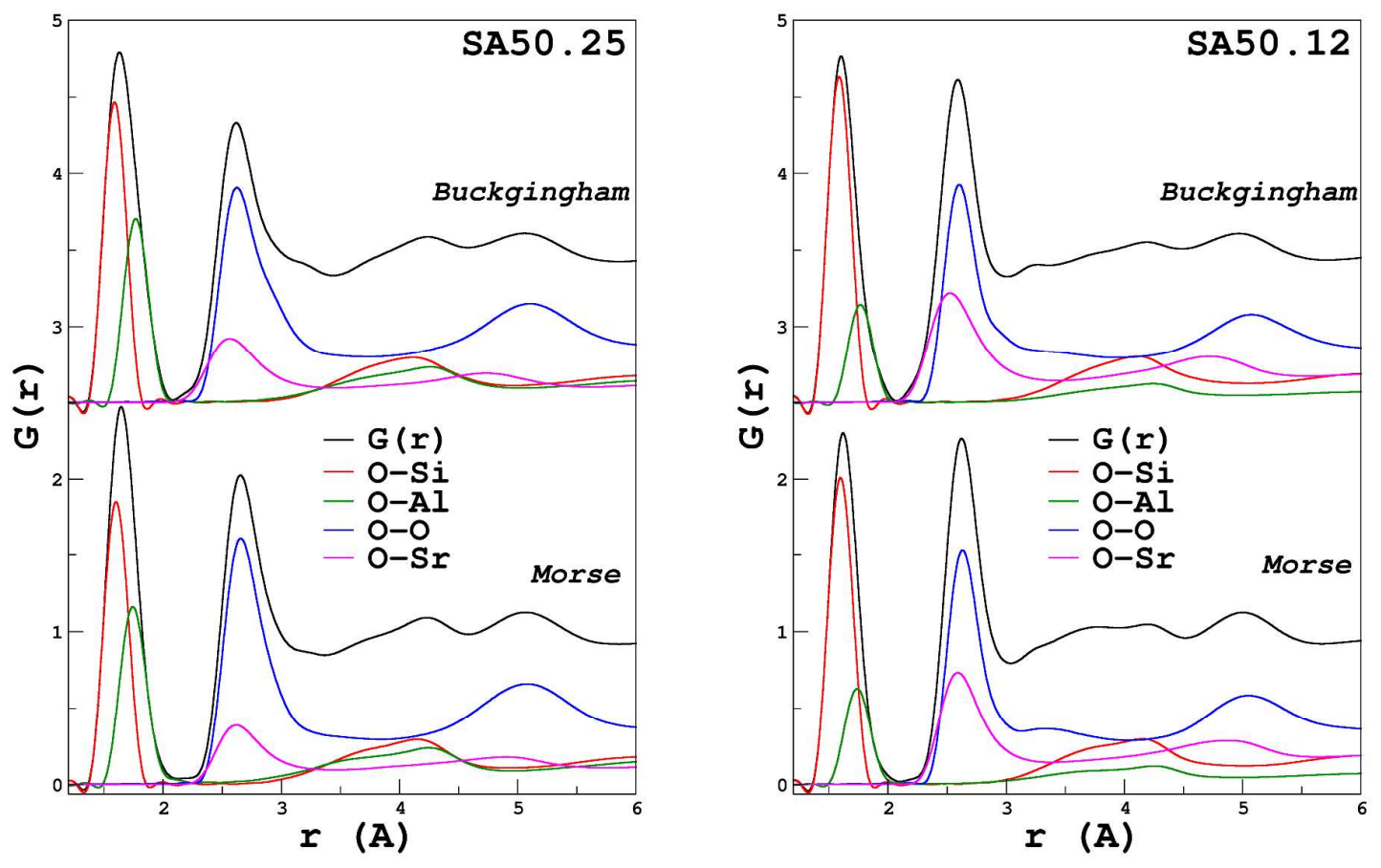

Figure 4. Upper panel, Total pair distribution function for the $R=1$ (left) and $R=3$ (right) glass series. Partial and total radial distribution functions obtained from MD simulations with Buckingham and Morse potentials for two representative glass compositions (accounting for finite-q acquisition in the reciprocal space).

3.2.1 Neutron data. As shown Figure 4, the strongest peak in experimental $g(r)$ centered at 1.7-1.6 Å shows a systematic shift with silica content. Partial contributions obtained from MD show that this peak is made up of the contribution of the $\mathrm{Si}-\mathrm{O}$ pairs $(1.60 \AA)$ and the $\mathrm{Al}-\mathrm{O}$ pairs $\left(1.75 \AA\right.$ ) , in agreement with earlier computational and experimental studies. ${ }^{2-4,7,18,57-60}$ The position of the $\mathrm{Si}-\mathrm{O}$ and $\mathrm{Al}-\mathrm{O}$ peak is constant across the calculated compositional range, and changes in the first peak of $g(r)$ are therefore mainly reflective of the Si/Al variations in composition. The second peak of the radial distribution is located at around $2.6 \AA$ and this peak is mainly a result of the $\mathrm{O}-\mathrm{O}$ and $\mathrm{Sr}-\mathrm{O}$ correlation centered at $2.65 \AA$ and $2.44 \AA$, respectively. Further peaks are smoother and are the result of more complex mixtures involving mainly second neighborhood contributions O-X pairs and Si-Si pairs (at around 3.2 $\AA$ ) are not analyzed here. It can be noticed that the broadening of the second peak in 
experimental $G(r)$ (dashed lines at about $2.6 \AA$ ) for higher Al content can be ascribed, according to $\mathrm{MD}$ simulations, to $\mathrm{O}-(\mathrm{Al})-\mathrm{O}$ distances. $\mathrm{X}-\mathrm{O}$ bond lengths extracted from computed partial radial distribution functions (RDF), as generated by the MD simulations, are gathered in Table 4. The values are given for two representative glass compositions together with averaged values over all glass compositions of each glass series. Because of the non-negligible influence of the atomic speciation on the bond lengths, it was systematically taken into account (but only non-negligible populations are given).

Table 4. Bond Lengths extracted from Partial RDFs (Peak Maximum and in parentheses Half Width at the Middle Height) for Two Representative Compositions (SA50.25 R=1 and SA50.12 R=3) and Averaged Values over all Glass Compositions (Buck. is the Buckingham model)

\begin{tabular}{|c|c|c|c|c|c|c|c|c|}
\hline \multirow{2}{*}{$\begin{array}{l}\text { Bond } \\
\text { length } \\
(\AA)\end{array}$} & \multicolumn{2}{|c|}{ SA50.25 } & \multicolumn{2}{|c|}{ SA50.12 } & \multicolumn{2}{|c|}{ Average $\mathrm{R}=1$} & \multicolumn{2}{|c|}{ Average $\mathrm{R}=\mathbf{3}$} \\
\hline & Buck. & Morse & Buck. & Morse & Buck. & Morse & Buck. & Morse \\
\hline $\mathrm{Si}-\mathrm{O}^{[2]}$ & $\begin{array}{c}1.60 \\
(0.04)\end{array}$ & $\begin{array}{c}1.62 \\
(0.05)\end{array}$ & $\begin{array}{c}1.61 \\
(0.04)\end{array}$ & $\begin{array}{c}1.62 \\
(0.05)\end{array}$ & $\begin{array}{c}1.60 \\
(0.04)\end{array}$ & $\begin{array}{c}1.62 \\
(0.05)\end{array}$ & $\begin{array}{c}1.61 \\
(0.04)\end{array}$ & $\begin{array}{c}1.62 \\
(0.05)\end{array}$ \\
\hline $\mathrm{Si}-\mathrm{O}^{[1]}$ & $\begin{array}{c}1.57 \\
(0.03)\end{array}$ & $\begin{array}{c}1.58 \\
(0.04)\end{array}$ & $\begin{array}{c}1.57 \\
(0.03)\end{array}$ & $\begin{array}{c}1.58 \\
(0.04)\end{array}$ & $\begin{array}{c}1.57 \\
(0.03)\end{array}$ & $\begin{array}{c}1.58 \\
(0.04)\end{array}$ & $\begin{array}{c}1.57 \\
(0.03)\end{array}$ & $\begin{array}{c}1.58 \\
(0.04)\end{array}$ \\
\hline$A I^{I V}-0$ & $\begin{array}{c}1.79 \\
(0.06)\end{array}$ & $\begin{array}{c}1.76 \\
(0.07)\end{array}$ & $\begin{array}{c}1.78 \\
(0.05)\end{array}$ & $\begin{array}{c}1.76 \\
(0.06)\end{array}$ & $\begin{array}{c}1.79 \\
(0.06)\end{array}$ & $\begin{array}{c}1.76 \\
(0.07)\end{array}$ & $\begin{array}{c}1.78 \\
(0.05)\end{array}$ & $\begin{array}{c}1.76 \\
(0.06)\end{array}$ \\
\hline$A I^{v}-O$ & $\begin{array}{c}1.89 \\
(0.11)\end{array}$ & $\begin{array}{c}1.89 \\
(0.13)\end{array}$ & $\begin{array}{c}1.90 \\
(0.10)\end{array}$ & $\begin{array}{c}1.89 \\
(0.12)\end{array}$ & $\begin{array}{c}1.90 \\
(0.11)\end{array}$ & $\begin{array}{c}1.89 \\
(0.13)\end{array}$ & $\begin{array}{c}1.90 \\
(0.10)\end{array}$ & $\begin{array}{c}1.89 \\
(0.12)\end{array}$ \\
\hline $\mathrm{Sr}-\mathrm{O}^{[2]}$ & $\begin{array}{c}2.83 \\
(0.31)\end{array}$ & $\begin{array}{c}2.92 \\
(0.29)\end{array}$ & $\begin{array}{c}2.90 \\
(0.31)\end{array}$ & $\begin{array}{c}2.94 \\
(0.29)\end{array}$ & $\begin{array}{c}2.84 \\
(0.31)\end{array}$ & $\begin{array}{c}2.91 \\
(0.29)\end{array}$ & $\begin{array}{c}2.89 \\
(0.31)\end{array}$ & $\begin{array}{c}2.93 \\
(0.29)\end{array}$ \\
\hline $\mathrm{Sr}-\mathrm{O}^{[1]}$ & $\begin{array}{c}2.56 \\
(0.24)\end{array}$ & $\begin{array}{c}2.67 \\
(0.23)\end{array}$ & $\begin{array}{c}2.62 \\
(0.27)\end{array}$ & $\begin{array}{c}2.71 \\
(0.25)\end{array}$ & $\begin{array}{c}2.54 \\
(0.24)\end{array}$ & $\begin{array}{c}2.67 \\
(0.23)\end{array}$ & $\begin{array}{c}2.62 \\
(0.27)\end{array}$ & $\begin{array}{c}2.71 \\
(0.25)\end{array}$ \\
\hline
\end{tabular}

As already noticed in previous MD studies ${ }^{61-63}, \mathrm{Si}-\mathrm{O}^{[1]}$ bonds are shorter by about $0.03-0.04 \AA$ with respect $\mathrm{Si}-\mathrm{O}^{[2]}\left(\mathrm{O}^{[2]}\right.$ represents bridging oxygens) bonds; the Morse potential predicts slightly longer distance (0.01-0.02 $\AA$ ) than Buckingham. Concerning aluminum, $\mathrm{Al}^{\mathrm{V}}$-O distance exceeds $\mathrm{Al}^{\mathrm{IV}}-\mathrm{O}$ one by about $0.1 \AA$ for Buckingham and $0.12 \AA$ for Morse model. As detailed in the Supporting Information, the larger dispersion in $\mathrm{Al}^{\mathrm{V}}-\mathrm{O}$ bond lengths is a consequence of the fact that in most cases, among the five bond lengths, two bonds were found to be systematically much longer than the three shorter ones, which turn out to be rather close 
$\mathrm{Al}^{\mathrm{IV}}-\mathrm{O}$ distances. Bond lengths for $\mathrm{Si}-\mathrm{O}^{[2]}, \mathrm{Si}-\mathrm{O}^{[1]}, \mathrm{Al}^{\mathrm{V}}-\mathrm{O}$ and $\mathrm{Al}^{\mathrm{IV}}-\mathrm{O}$ were found to be - on average - quite constant across all studied compositions for both potential sets. This contrasts the behavior of $\mathrm{Sr}-\mathrm{O}$ distances which show strong variations with composition as detailed in the Supporting Information and quite significant differences are observed between the two potentials sets (Table 4). $\mathrm{Sr}-\mathrm{O}^{[2]}$ and $\mathrm{Sr}-\mathrm{O}^{[1]}$ distances are longer for the Morse potential sets versus Buckingham ones, with differences in between 0.1 and $0.15 \AA$. In these respects, Buckingham potential sets seems to favor Sr-O interactions (and particularly $\mathrm{Sr}-\mathrm{O}^{[1]}$ ) with respect to the Morse potentials sets. Larger dispersion values are observed for Sr-O distances and highlights the fact the first coordination sphere of $\mathrm{Sr}$ is less well-defined (vide infra) as generally observed for alkali and alkaline-earth. ${ }^{4,62}$ As will be seen later, this pronounced difference between the two potential sets results in rather different population oxygen species $\mathrm{O}^{[1]-[3]}$, but also on strontium coordination numbers, as discussed in the next section.

3.2.2 Oxygen environment. Variations of the oxygen speciation populations are summarized in Figure 5. For $\mathrm{R}=1$ compositions, both models show a non-negligible amount of $\mathrm{O}^{[1]}$ (NBO) and $\mathrm{O}^{[3]}(\mathrm{TBO})$ which concentration decreases with the Si content. At high aluminum content, the Morse potential sets shows a much higher concentration of $\mathrm{O}^{[1]}$ and $\mathrm{O}^{[3]}(\sim 20 \%)$ than Buckingham ( 10\%). Globally, if more depolymerized structures are predicted with the Morse potential sets (in terms of $\mathrm{O}^{[1]}$ concentration), they also contain a much higher content of $\mathrm{O}^{[3]}$. The presence of a non-negligible amount of $\mathrm{O}^{[1]}$ in tectosilicate compositions has been experimentally observed for several other glass compositions, ${ }^{13,14,64}$ requiring the formation of other species such as $\mathrm{AlO}_{5}$ (see below) or $\mathrm{O}^{[3]}$ to maintain the local charge balance. 


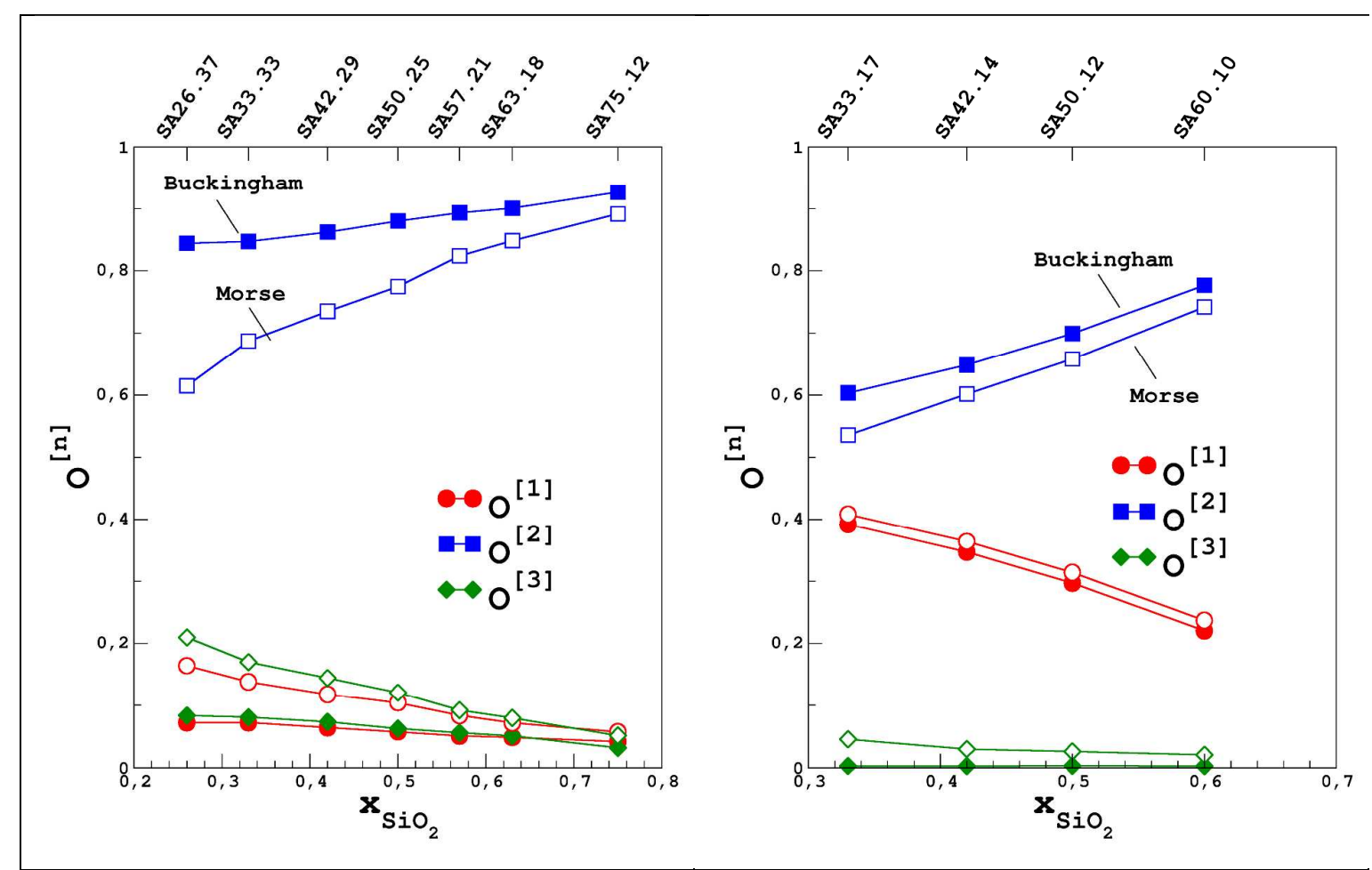

Figure 5. Variations of the oxygen speciation populations with the glass compositions predicted with the two potential models studied. (Closed symbols: Buckingham; Open symbols: Morse).

For $\mathrm{R}=3$, if nearly identical $\mathrm{O}^{[1]}$ populations are predicted for both models, only the Morse potential predicts $\mathrm{O}^{[3]}(\sim 5 \%)$ resulting in a lowering of the $\mathrm{O}^{[2]}$ concentration by $5-10 \%$ as compared with Buckingham model. As expected $\mathrm{O}^{[1]}$ population decreases linearly with the silica content (or equivalently increases with the SrO content).

3.2.3 Aluminum environment. Variations of the $\mathrm{Al}$ speciation populations $\left(\mathrm{AlO}_{4}, \mathrm{AlO}_{5}\right.$ and $\mathrm{AlO}_{6}$ ) are displayed in Figure 6. For $\mathrm{R}=1$ compositions, tetrahedral $\mathrm{Al}$ is dominant with a nearly constant concentration of $5 \% \mathrm{AlO}_{5}$ for the Buckingham potential, in good agreement with NMR experiments, whereas Morse Potential sets predict much higher $\mathrm{AlO}_{5}$ population which decreases with the silica content (in addition to a small fraction of $\mathrm{AlO}_{6}$ following the same trend). At high silica content, both models become equivalent. No noticeable population of $\mathrm{NBO}$ on the $\mathrm{AlO}_{4}$ nor the $\mathrm{AlO}_{5}$ or $\mathrm{AlO}_{6}$ units is observed, in agreement with $\mathrm{Al}-$ 
NBO being energetically less favorable than $\mathrm{Si}-\mathrm{O}^{[1]}$ bonds. ${ }^{1,64}$ For $\mathrm{R}=3$ compositions, a dominant $\mathrm{AlO}_{4}$ population is predicted but with a nearly constant $\mathrm{AlO}_{5}$ population: $10 \%$ for the Morse model and 5\% for the Buckingham model, both in quite good qualitative agreement with the NMR experiments. In this respect, MD simulations corroborate the presence of $\mathrm{AlO}_{5}$, even with a large excess of SrO.
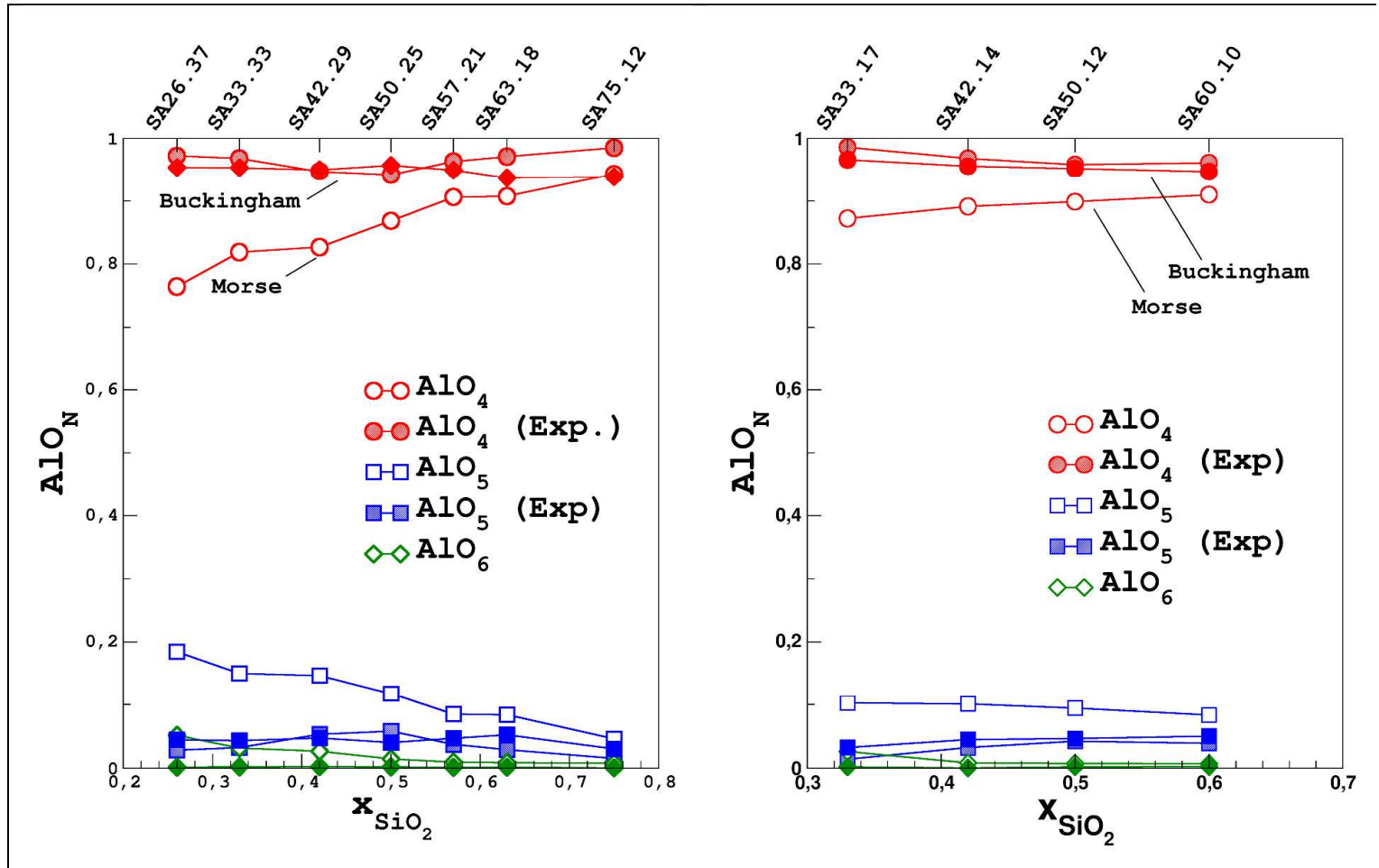

Figure 6. Variations of the Al speciation populations $\left(A / O_{p}\right)$ with the glass composition for the two potential sets studied. (Closed symbols: Buckingham; Open symbols: Morse).

O-Al-O bond angle distributions are displayed in Figure 7 for two representative glass compositions. Four-folded $\mathrm{Al}$ are in rather regular tetrahedral units showing a narrow distribution of O-Al-O angles centered around $109.5^{\circ}$. For 5-folded atoms, a broader O-Al-O angle distribution is observed with the main peak at $90^{\circ}$ followed a very broad peak a $170^{\circ}$. This is indicative of a bipyramidal rather than a squared based pyramid geometry. The two 
potentials yield close O-Al-O bond angle distribution (BAD); with a slightly broader peak at $90^{\circ}$ for $\mathrm{AlO}_{5}$ for the Morse potential, reflective of more distorted units.

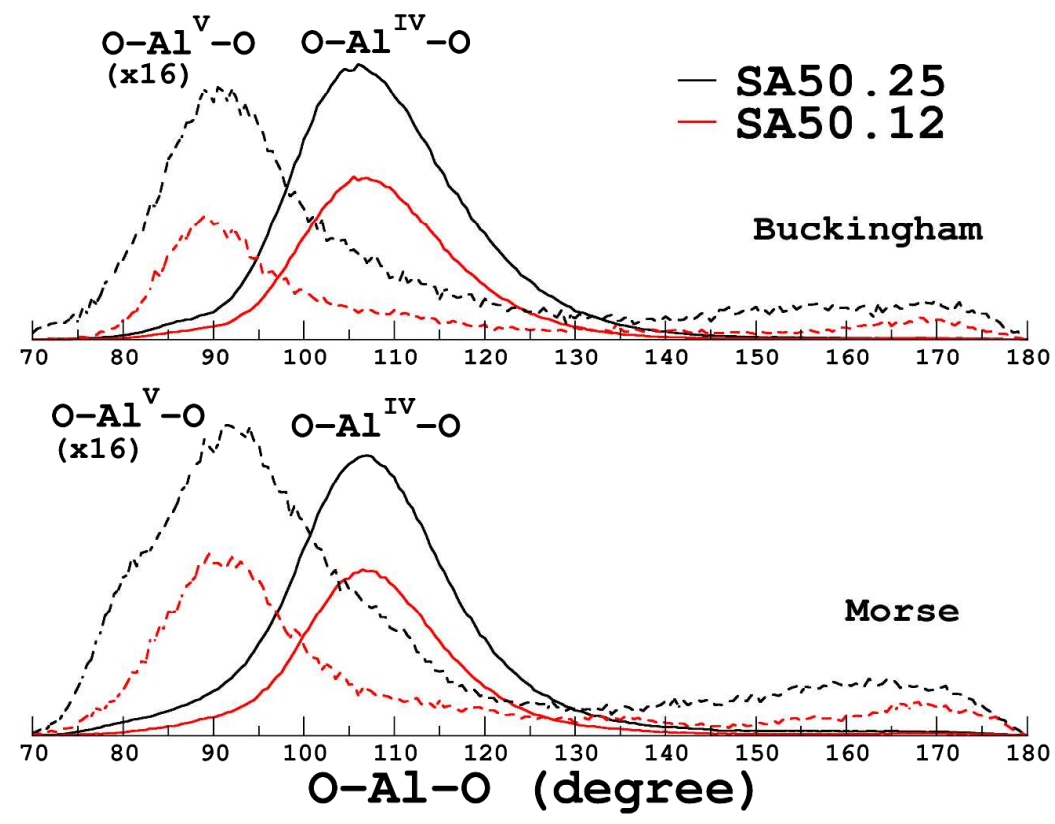

Figure 7. $O-A I^{I V}-O$ and $O-A I^{V}-O$ Bond Angle distribution for two representative glass compositions.

Figure 5 and Figure 6 suggest that the amount of $\mathrm{AlO}_{5}$ units correlate to the amount of $\mathrm{O}^{[1]}$ and $\mathrm{O}^{[3]}$. For Morse potentials, were the $\mathrm{AlO}_{5}$ fraction span a wider range of values, $\mathrm{O}^{[1],[3]}$ populations are indeed found to correlate to $\mathrm{AlO}_{5}$ fraction (see Supporting Information). This point will be further discussed below in connection with the presence of small rings.

3.2.4 Silicon environment. O-Si-O bond angle distributions (shown Supporting Information) show that for both potential sets silicon tetrahedral units are well ordered with a narrow distribution around $109.5^{\circ}$ (100\% of the silicon atoms are in tetrahedral units). The variations of the $\mathrm{Q}^{(\mathrm{n})}$ units with glass compositions are displayed in Figure 8; note that only $\mathrm{Q}^{(2)}, \mathrm{Q}^{(3)}$ and $Q^{(4)}$ units are present. 


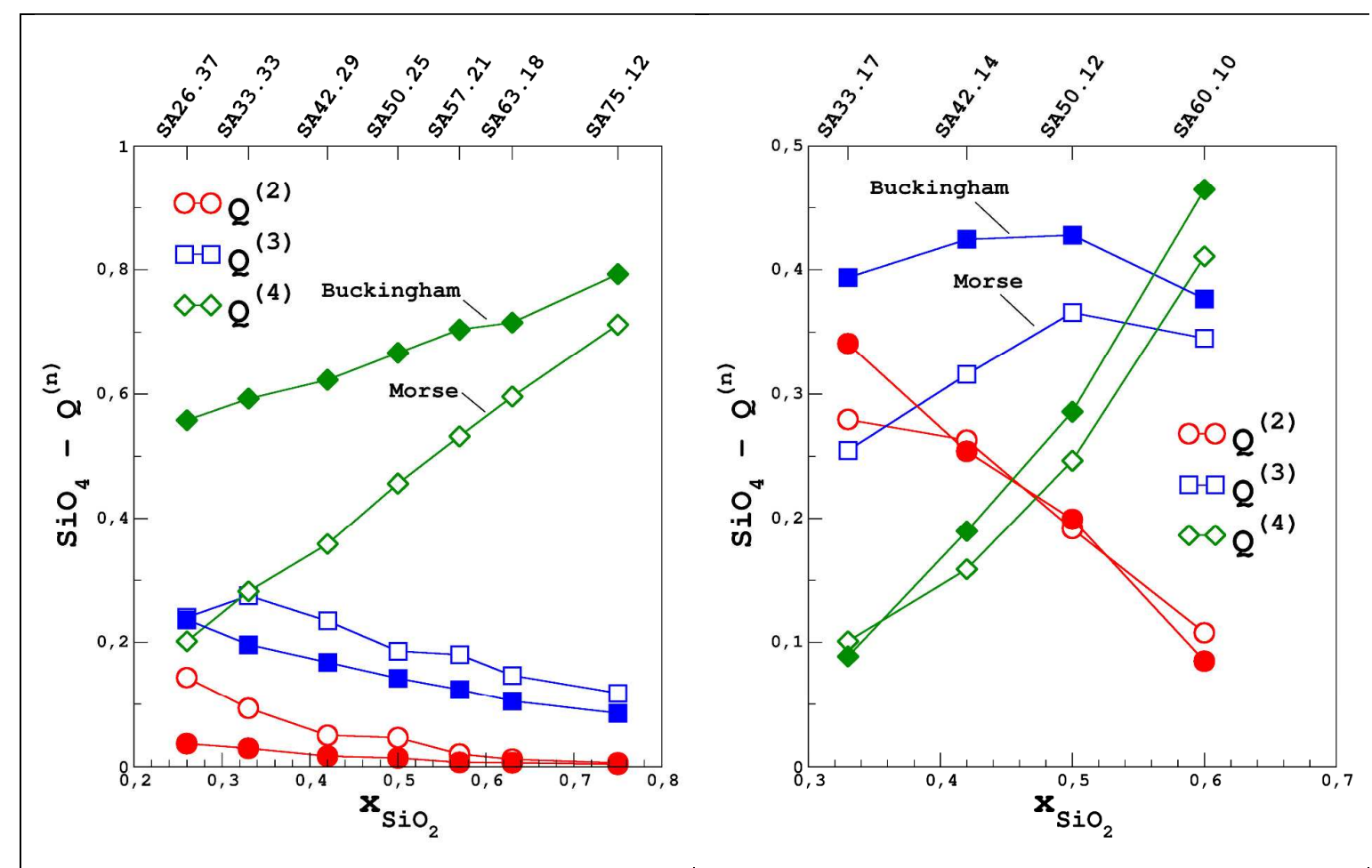

Figure 8. Variations of the $Q^{(n)}$ fractions with the glass composition (Left $R=1$ and right $R=3$ glass series). (Closed symbols: Buckingham; Open symbols: Morse).

For $\mathrm{R}=1$ compositions, despite the exact charge balance condition, a significant fraction of $\mathrm{Si}$ tetrahedral units are disconnected from the network $\left(\mathrm{O}^{[1]}\right)$ with a marked difference between the two potential sets in term of the $Q^{(4)}$ units. As expected from the oxygen speciation analysis (Figure 5), the Morse potential sets predict a much less polymerized network, but both exhibit a global increase $Q^{(4)}$ with silica content. For low silicon content $(<$ $50 \%)$, the Buckingham model favors a bimodal distribution of $Q^{(n)}$ units $\left(Q^{(3)}\right.$ and $\left.Q^{(4)}\right)$ whereas a trimodal distribution is predicted for the Morse model, with $\mathrm{Q}^{(2)}$ units. For high silicon content, both models converge to a bimodal distribution of $\mathrm{Q}^{(3)}$ and $\mathrm{Q}^{(4)}$ units.

For $\mathrm{R}=3$ compositions, $\mathrm{Q}^{(3)}$ units are the most frequent with a concentration ranging from 30 to $40 \%$. The linear increase of $Q^{(4)}$ at the expense of the $Q^{(2)}$ units with the silica content is similar for both potential sets. 
3.2.5 Strontium environment. Comparison between the Sr-BO and Sr-NBO partial RDF for the two potential sets is displayed in Figure 9 for two representative glass compositions. The decay of the partial Sr-NBO RDF to zero and its smaller width (than Sr-BO) reveal that the environment of strontium atoms is better defined when accounting for the NBOs only. The O-Sr-O angle distributions show standard shapes for modifier cations (see Supporting Information), characterized by a broad distribution covering the range $40^{\circ}-180^{\circ}$ with peak maxima at $50^{\circ}, 80^{\circ} 110^{\circ}$, thus reflective of the variety of $\mathrm{Sr}$ polyhedral types, as also illustrated by the broad distribution of the coordination numbers $(\mathrm{CN})$ displayed in Figure 9 (right panel). A large dispersion of CNs is observed with values ranging from 6 to 10 (with max $\mathrm{CN}$ at $~ 7-8)$. Such high $\mathrm{CN}$ values can be understood considering the relatively medium cation field strength (CFS) of strontium and our simulations are in agreement with previous MD studies of more complex glass compositions. ${ }^{59,65,66}$ A more detailed analysis of CNs (Figure 10) shows that for $\mathrm{R}=1$ strontium environment is dominated by bridging oxygen atoms, in agreement with the low amount of $\mathrm{O}^{[1]}$ expected in this system, whereas for $\mathrm{R}=3$ the first coordination sphere is almost equally shared by $\mathrm{O}^{[1]}$ and $\mathrm{O}^{[2]}$ atoms. This first coordination analysis underlines that $\mathrm{Sr}$ atoms (but this also applies to any modifier cation) cannot be unambiguously classified as network modifier nor charge compensator solely; its structural role is more likely to be in between, depending upon the relative contribution of $\mathrm{O}^{[1]}$ and $\mathrm{O}^{[2]}$ atom to its $\mathrm{CN}$ value (note that Sr sees only few $\mathrm{O}^{[3]}$ ). 


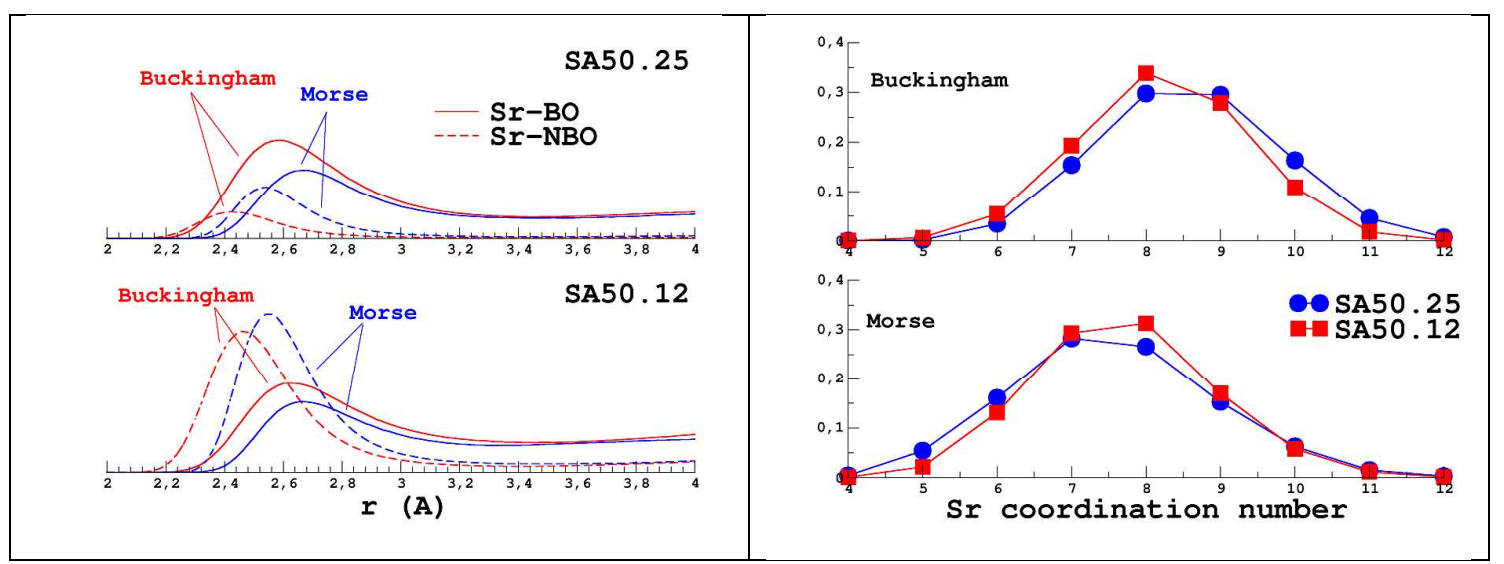

Figure 9. Left panel: example of decomposition of the $\mathrm{Sr}$-O partial radial distribution function into $\mathrm{Sr}-\mathrm{O}^{[1]}$ and $\mathrm{Sr}-\mathrm{O}^{[2]}$ contributions for two representative compositions as obtained in MD simulations. Right panel: distribution of strontium coordination numbers.

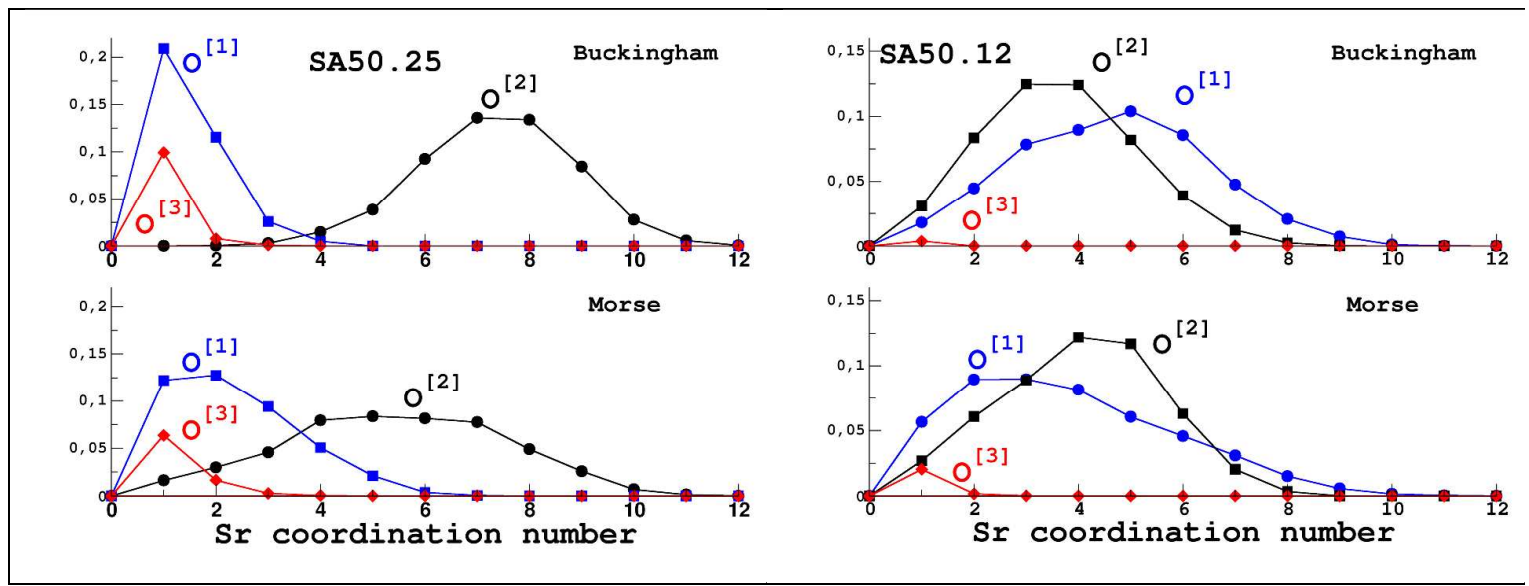

Figure 10. Decomposition of the strontium coordination number distributions for two glass compositions in terms of non-bridging oxygen $\left(\mathrm{O}^{[1]}\right)$, bridging-oxygen $\left(\mathrm{O}^{[2]}\right)$ and tricoordinated oxygen atoms $\left(O^{[3]}\right)$. 

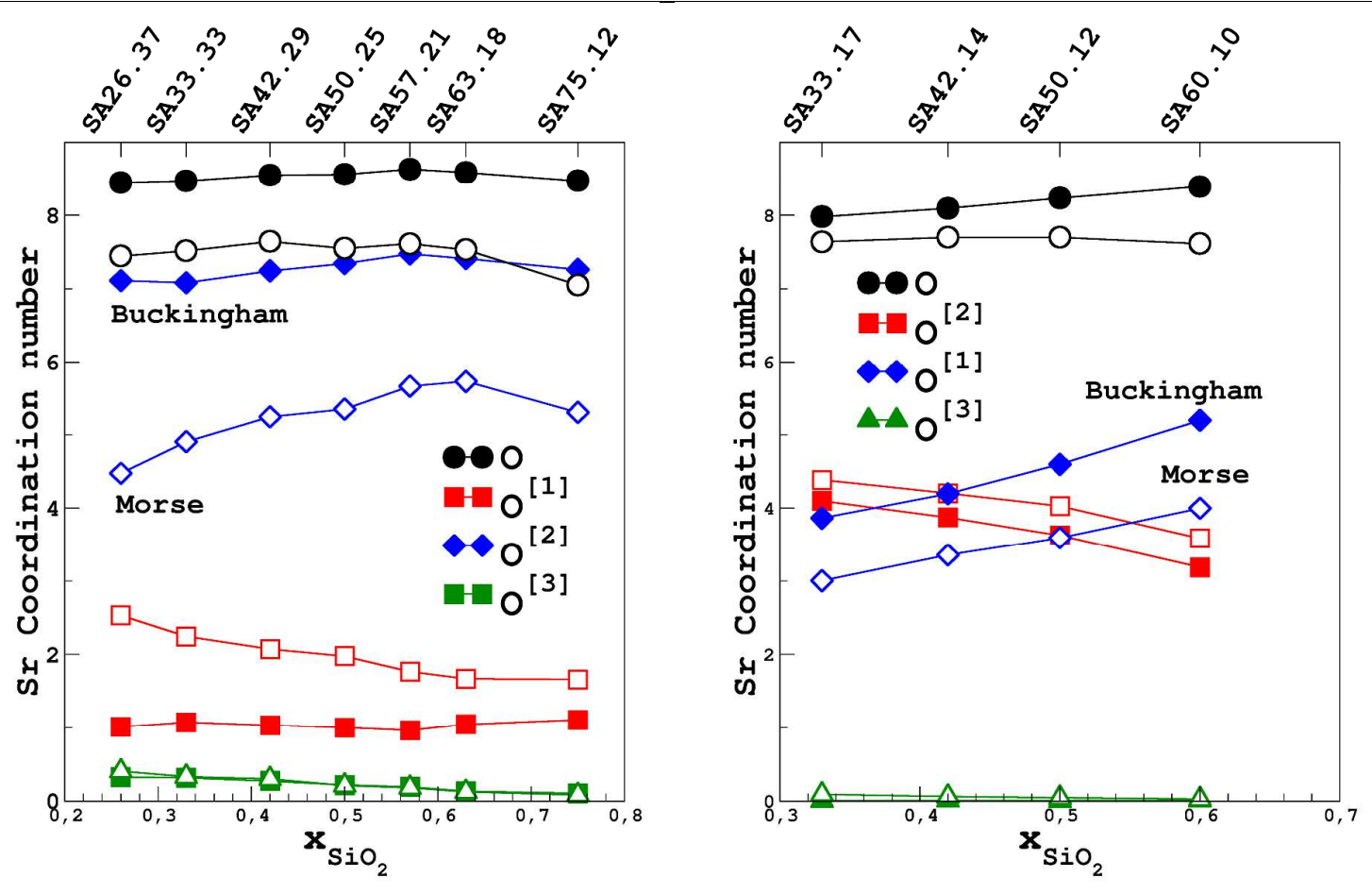

Figure 11. Variation of the averaged strontium coordination numbers with the glass composition (Closed symbols: Buckingham; Open symbols: Morse).

For all glass compositions, the decomposition of the average $\mathrm{CN}_{\mathrm{O}}$ in terms of bridging $\left(\mathrm{O}^{[2]}\right)$, non-bridging $\left(\mathrm{O}^{[1]}\right)$ and tricoordinated $\left(\mathrm{O}^{[3]}\right)$ oxygen atoms are shown in Figure 11 . For the $\mathrm{R}=$ 1 glass series, $\mathrm{CN}_{\mathrm{O}}$ is rather constant ( 7-8) with a difference of about 1 between the two potential sets. This difference is more pronounced (almost 2) when considering bridgingoxygen only but partially compensated by an inverted trend for $\mathrm{O}^{[1]}$ showing a difference between -0.5 and -1 . Thus, the Morse potential sets favor $\mathrm{Sr}-\mathrm{O}^{[1]}$ contacts compared to the Buckingham potential sets. This leads to a higher number of coordinated $\mathrm{O}^{[2]}$ (and globally of oxygen) for the latter model. In contrast, both models have a similar trend in terms of $\mathrm{O}^{[3]}$ with a value varying from 0.4 to 0.1 with silica content increasing.

Similar differences between both potential sets are observed for the $\mathrm{R}=3$ glass series but are less pronounced. As expected from the dominant modifier role of strontium for $R=3$, contribution of $\mathrm{O}^{[1]}$ is much higher $(\sim 4)$ but also quite close to $\mathrm{O}^{[2]}$ which is in turn much 
lower ( 4-5) than for $\mathrm{R}=1$ glasses. This yields a global coordination number $\mathrm{CN}_{0}$ of 8 , very close to the $\mathrm{R}=1$ glass series value. This number is nearly constant as a result of an increase of $\mathrm{O}^{[2]}$ contribution which is partially compensated by a decrease of $\mathrm{O}^{[1]}$.

These results suggests that the presence of $\mathrm{O}^{[3]}$ units is not correlated to Sr-O interactions (which differs between the two potential models) but more likely related to Al-O interactions: Sr-O bond lengths are rather similar for the two potential sets (Table 4). Experimentally, presence of $\mathrm{O}^{[3]}$ is expected based on the presence $\mathrm{AlO}_{5}$ units as observed by NMR (Figure 2). Spatial distribution of $\mathrm{O}^{[3]}$ within the simulation cell and their exact contribution to global charge compensation mechanisms will be investigated in a future work with the help of quantum chemical calculations.

In order to further analyze the $\mathrm{Sr}-\mathrm{O}$ contacts independently of populations of the various oxygen speciations which have to be shown to be governed by the short-range potential models we introduce a preference factor $P$ which accounts for the preferential contact of strontium cations with $\mathrm{O}^{[\mathrm{q}]}$ atoms. The latter is defined ${ }^{51,67,68}$ as

$$
P=\frac{N_{q}^{p}}{p \times x O^{[q]}}
$$

where $N_{q}^{p}$ is the number of coordinating oxygen $O^{[q]}$ of $\mathrm{SrO}_{\mathrm{p}}$ clusters and $x O^{[q]}$ is the fraction of $O^{[q]} . P>1$ means preferential interaction. The results of this analysis are shown in Figure 12 for the most abundant $\mathrm{SrO}_{p}$ clusters $(p=7$ for Morse and $p=8$ for Buckingham potential sets). Both potential sets give the same results for $\mathrm{O}^{[2]}$ and $\mathrm{O}^{[1]}$ whereas $\mathrm{Sr}$ - $\mathrm{O}^{[3]}$ contacts are more favored with the Buckingham potential sets.

For $\mathrm{R}=1$, a strong preference for $\mathrm{O}^{[1]}$ is noticed, increasing with silicon content, whereas interaction with $\mathrm{O}^{[2]}$ is almost constant and close to 1 , i.e. $\mathrm{O}^{[2]}$ are more likely to be randomly 
distributed around the strontium atoms. This behavior can be explained by the low content of $\mathrm{O}^{[1]}$ atoms which need to be charge compensated; the $\mathrm{O}^{[1]}$ concentration decrease with silica content manifests itself by an increase of the $\mathrm{O}^{[1]}$ preference factor. $\mathrm{Sr}-\mathrm{O}^{[3]}$ contacts are unfavored and nearly constant with the glass composition. For the $\mathrm{R}=3$ glasses, the higher strontium concentration results in a lower preference factor for NBO (but still > 1), also increasing with silica content, and to slightly unfavored $\mathrm{Sr}-\mathrm{O}^{[2]}$ contacts (but still close to random).

In conclusion, this analysis demonstrates that both potential sets yield similar behavior of preference factors for $\mathrm{Sr}-\mathrm{O}^{[2]}$ and $\mathrm{Sr}-\mathrm{O}^{[1]}$ contacts. This suggests that they are somewhat independent of the short repulsion terms, and most likely to be governed by Coulombic interactions. $\mathrm{O}^{[2]}$ are distributed almost randomly around the strontium atoms. The observed differences in $\mathrm{CN}_{\mathrm{O}[2]}$ and $\mathrm{CN}_{\mathrm{O}[1]}$ (Figure 11) seem to be therefore first a consequence of the global population of $\mathrm{O}^{[2]}$ and $\mathrm{O}^{[1]}$ which in turn depends on the chosen potential sets. 

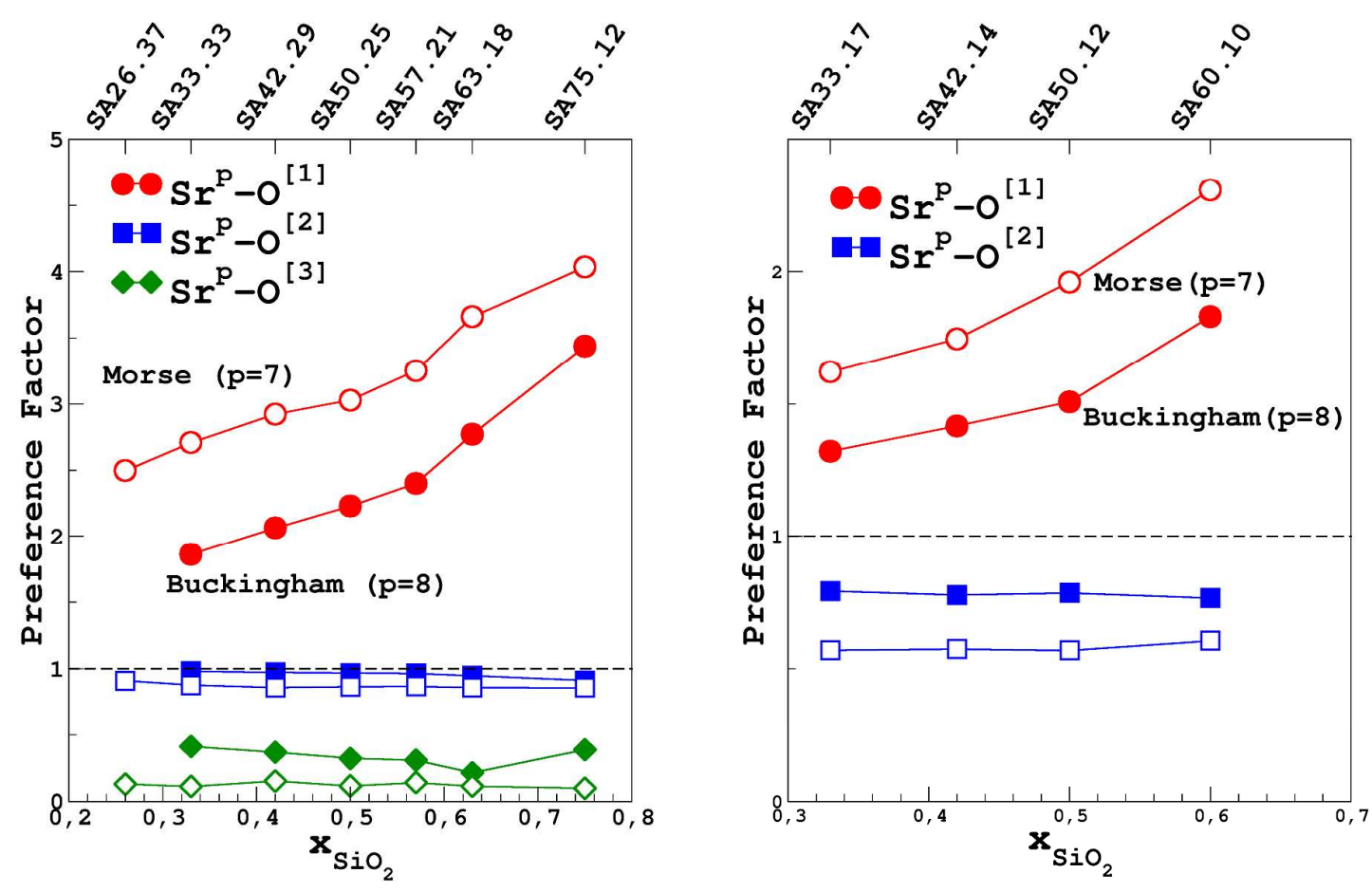

Figure 12. Variation of the preference factor $P(E q$. (4)) with the glass composition for the most populated $\mathrm{SrO}_{p}$ cluster (Closed symbols: Buckingham; Open symbols: Morse). Left $R=1$ and right $R=3$ glass series.

3.2.6 Al/Si mixing. To investigate the $\mathrm{Al} / \mathrm{Si}$ mixing, $\mathrm{T}-\mathrm{O}^{[2]}-\mathrm{T}^{\prime}\left(\mathrm{T}, \mathrm{T}^{\prime}=\mathrm{Al}, \mathrm{Si}\right)$ relative populations have been calculated and are displayed Figure 13. They vary in a similar way for both models across the calculated compositional range. It is important to note that the populations displayed corresponds to the conditional probabilities $p\left(T-O-T^{\prime} \mid O=O^{[2]}\right)$; in other words, this means that the dependence upon the total population of bridging oxygens, i.e., $p\left(O^{[2]}\right)$ (see Figure 5 ) has been compensated. For a comparison, variations of the total fraction of $\mathrm{T}-\mathrm{O}^{[2]}-\mathrm{T}^{\prime}$, that is $p\left(T-O-T^{\prime}\right)=p\left(T-O-T^{\prime} \mid O=O^{[2]}\right) \times p\left(O^{[2]}\right)$ are given in the Supporting Information.

Figure 13 highlights the fact the pairing of $\mathrm{Al} / \mathrm{Si}$ is independent on the potential sets chosen, even of the fractions of $O^{[n]}(n=1,2,3)$ species are strongly dependent on it. This suggests that $\mathrm{Al} / \mathrm{Si}$ are mainly governed by electrostatic (here, Coulombic) interactions. Comparison with a binomial model (dashed lines in Figure 13) indicates that the Al/Si mixing on bridging 
oxygen possess some ordering characteristics when aluminum is involved whereas Si-O-Si population follows closely the binomial model. Si-O-Al linkages are clearly favored in contrast to Al-O-Al ones, a fact which has been often observed experimentally. ${ }^{1,13,69,70}$

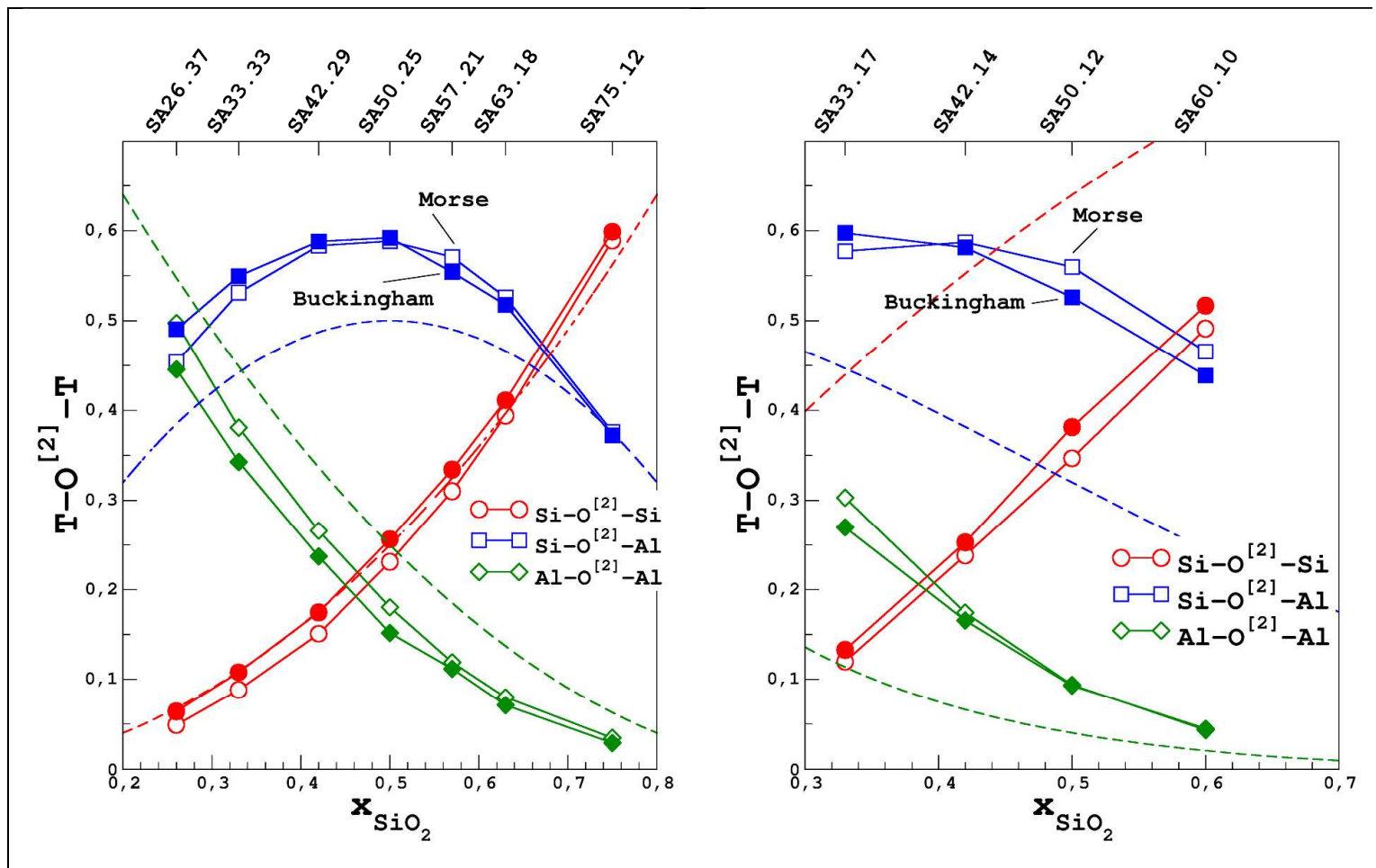

Figure 13. Variations of the $T-O^{[2]}-T$ relative populations ( $\left.T=A l, S i\right)$ with the glass compositions predicted by the two potential models studied. Dashed represents random probabilities calculated from the glass composition (i.e., binomial law).

Variations of $\mathrm{O}^{[1]}-\mathrm{T}$ reveals that in both models, $\mathrm{O}^{[1]}$ predominantly bounds to $\mathrm{Si}$, in agreement with experimental NMR observation (Figure 14). $\mathrm{O}^{[3]}$ population analysis confirms that $\mathrm{OAl}_{3}$ and $\mathrm{OAl}_{2} \mathrm{Si}$ are the most favorable configurations (Figure 15). 


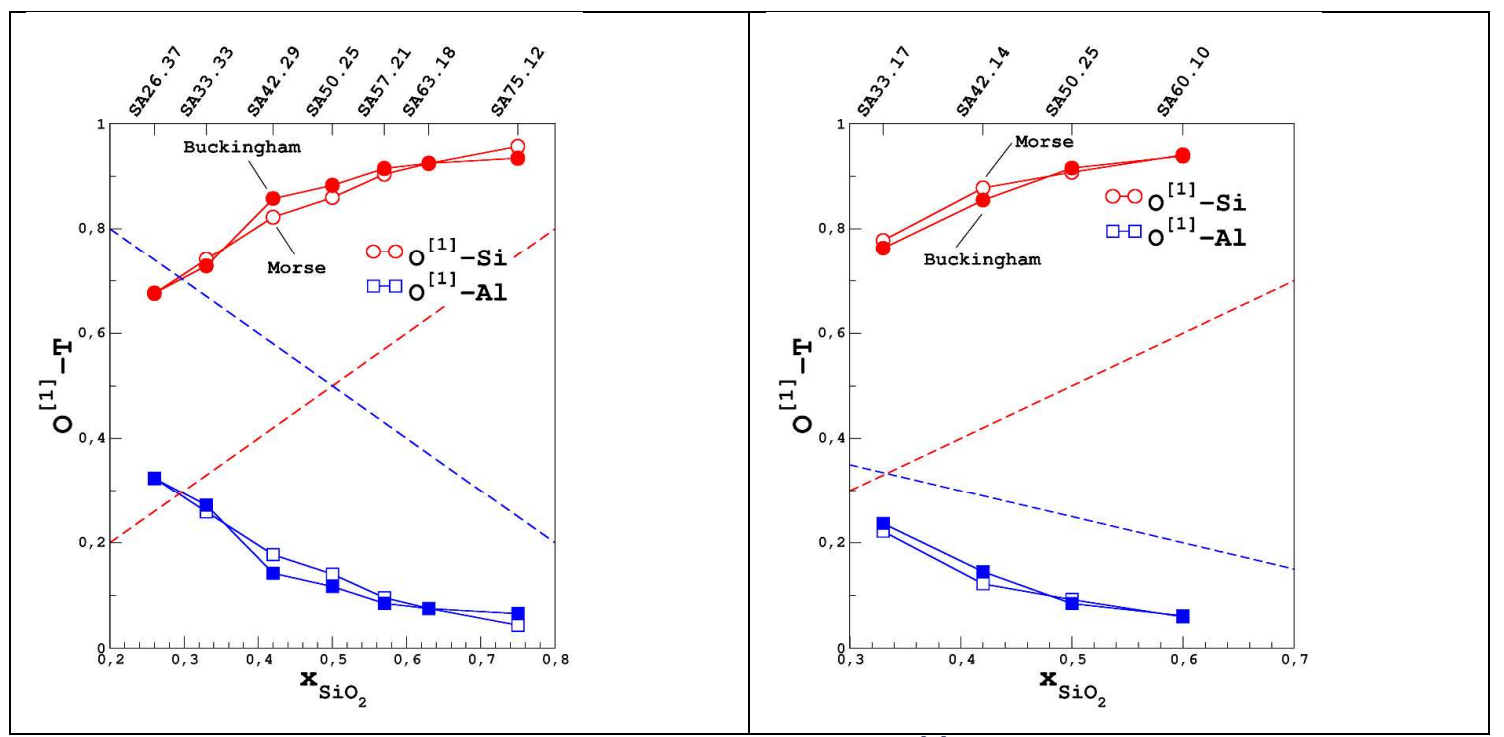

Figure 14: Variation of (left and middle panel) the $O^{[1]}-T$ populations $(T=A l, S i)$ with glass composition for the two potential sets studied. Dashed lines represents random probabilities calculated from the glass composition.

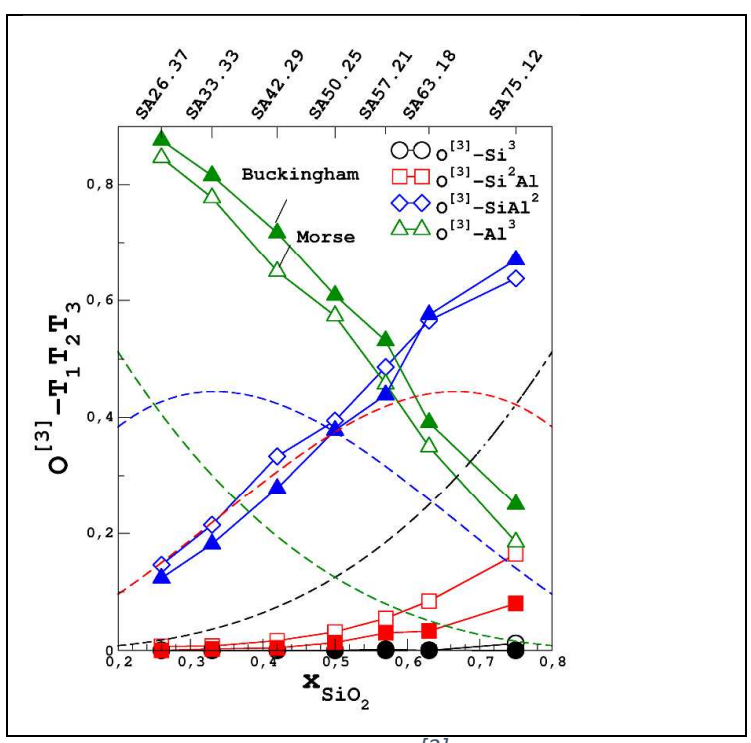

Figure 15. Variation of $O^{[3]}$ with glass composition for the two potential sets studied. Dashed lines represents probabilities calculated from the glass composition (i.e. random bonding to Al or Si atoms).

3.2.7 Bond angle distribution and primary ring structure. Bond angle distributions SiOSi, SiOAl and AIOAl are plotted in Figure 16 for two representative glass compositions from the $\mathrm{R}=1$ and $\mathrm{R}=3$ glass series. Left panel shows that both potential models produce similar shape. For $\mathrm{BO}$, the $\mathrm{BAD}$ extend from $120^{\circ}$ to $180^{\circ}$ with peak maxima at $140-150^{\circ}$ in the order 
SiOSi>SiOAl>AIOAl, they are standard values in aluminosilicate glasses. In the case of $\mathrm{O}^{[3]}, \mathrm{Al}-$ $\mathrm{O}^{[3]}-\mathrm{Si} \mathrm{BAD}$ shows a narrower distribution with peak maxima at $120^{\circ}$ whereas $\mathrm{Al}-\mathrm{O}^{[3]}-\mathrm{Al}$ has two maxima at $120^{\circ}$ and $90^{\circ}$. Right panel reveals that no clear correlation of the bond angle with the coordination number of the oxygen atom can be established, in contrast to other cations. $^{71}$
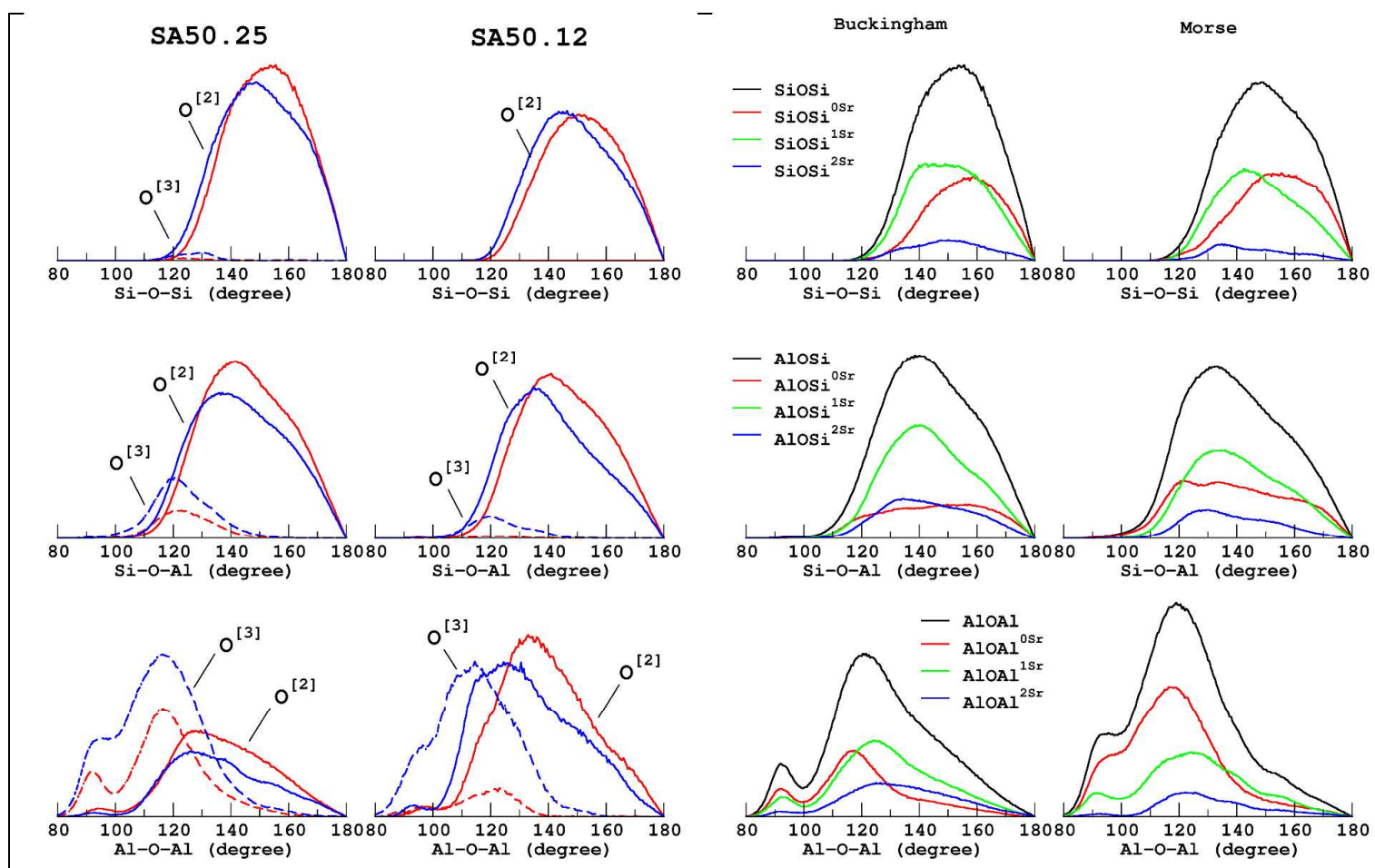

Figure 16. Left panel: SiOSi, SIOAl and AIOAl bond angle distributions (BAD) for two representative glass compositions for the two potential sets (blue lines: Morse and red lines: Buckingham). Right panel: For SA50.25 glass, analysis of the BAD in terms of the strontium coordination number of the oxygen (Buckingham potential sets). $\mathrm{TOT}^{\mathrm{NSr}}$ ( $T=\mathrm{Si}$ or Al) represents the BAD for oxygen atoms coordinated by $N$ strontium atoms.

To establish whether a correlation exists between ring size and coordination number of aluminum $\left(\mathrm{AlO}_{5,6}\right)$ or tricoordinated oxygen $\left(\mathrm{O}^{[3]}\right)$, a primary ring search has been performed by shortest-path analysis. For silicon $\mathrm{SiO}_{4}$, aluminum $\mathrm{AlO}_{4,5}$ and oxygen $\mathrm{O}^{[2],[3]}$ atoms, Figure 17 and Figure 18 show the fraction of each units considered in a given primary ring size. 
For $\mathrm{SiO}_{4}$ units, across all compositions ( $\mathrm{R}=1$ and $\mathrm{R}=3$ ), 8-fold rings dominates with an opening of the structure for higher silica content: the 10-fold ring population increases at the expense of the 6-fold rings. For $\mathrm{AlO}_{4}$ units, a similar behavior is observed between the two glass series but with higher population of 6 -fold rings and about $10 \%$ of the $\mathrm{AlO}_{4}$ are involved in edge-sharing (4-fold ring) configurations. In the case of $\mathrm{AlO}_{5}$ for the $\mathrm{R}=1$ compositions, higher coordination states are primarily involved in edge-sharing configurations (approx. $70 \%$ ) and in 6-fold rings (approx. 20\%). For the $\mathrm{R}=3$ glass series, the two potential sets exhibit significant differences: Morse model strongly favors edge-sharing configurations whereas Buckingham model favors 6 and 8-fold rings.

Concerning the oxygen (Figure 18), bridging oxygens $\mathrm{O}^{[2]}$ are mainly involved in 8 to 10 -fold rings, with 6-fold rings decreasing with the silica content. This trend is observed for the two glass series. This confirms that at higher aluminum content a more connected network is predicted. $\mathrm{O}^{[3]}$ are equally shared between 4 and 6 -fold rings $(6$ and 8 -fold rings, respectively) for the $R=1$ compositions ( $R=3$, respectively), with slight differences between the two potential models.

This analysis suggests that $\mathrm{AlO}_{5}$ together with $\mathrm{O}^{[3]}$ are mainly responsible for the formation of small ring structures, especially the formation of edge-sharing configurations and, to a lesser extent, of six-membered rings. A quantitative analysis of the charge distribution would be of interest to decipher their exact contribution to the global and local charge balance mechanisms, especially for the $\mathrm{R}=1$ compositions. As requiring more sophisticated methods to be employed such as DFT calculations and ab-initio molecular dynamics, such a work is in progress and will be presented elsewhere. 

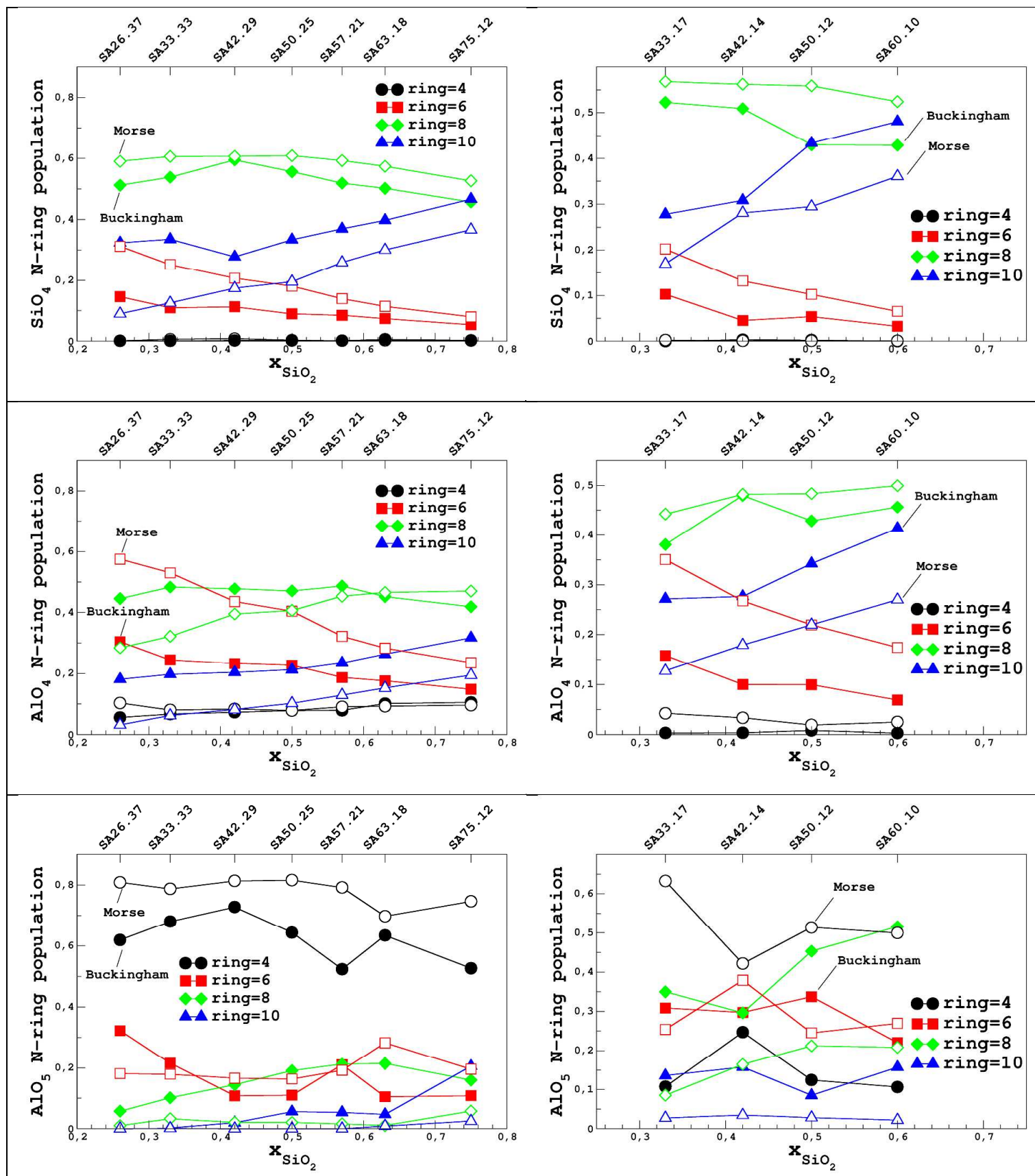

Figure 17. Variations with the glass composition of the ring size populations for tetrahedral silicon (top), tetrahedral aluminum (middle) and five-fold coordinated aluminum (bottom). Only small ring-sizes (which are also the most populated) are shown. Open and filled symbols for the Morse and Buckingham potential sets, respectively. 


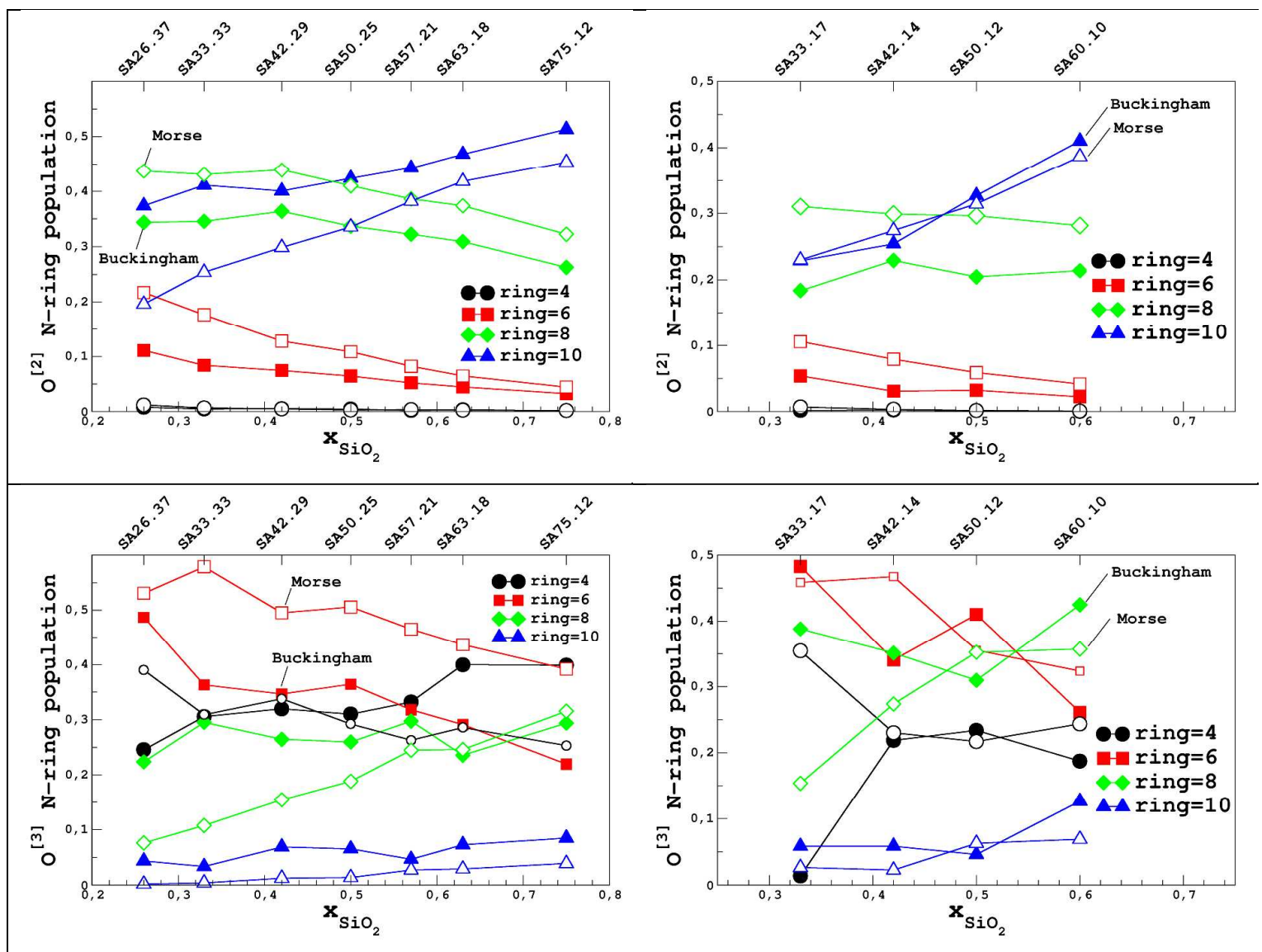

Figure 18. Variations with the glass composition of the ring-sizes of oxygen species: bridgingoxygen $O^{[2]}$ (upper) and tri-coordinated oxygen $O^{[3]}$ (lower) atoms. Open and filled symbols for the Morse and Buckingham potential sets, respectively.

\section{Conclusion}

Molecular dynamics simulations have been performed to investigate the structure of strontium aluminosilicate glasses. Two popular potential forms are compared for the shortrange interactions: the Morse and Buckingham forms. For both models, a good agreement is obtained with the neutron diffraction data and NMR experiments: aluminum is predominantly in tetrahedral form with a small amount (few \%) of fivefold units, as previously experimentally observed in calcium aluminate silicate glasses. ${ }^{10} \mathrm{~A}$ continuous decrease of ${ }^{27} \mathrm{Al}$ isotropic chemical shift in $\mathrm{AlO}_{4}$ units with the $\mathrm{Si} / \mathrm{Al}$ ratio is observed, mostly dictated by the $\mathrm{Al} / \mathrm{Si}$ mixing and in agreement with previous NMR studies in aluminosilicates. Similarly, ${ }^{29} \mathrm{Si}$ isotropic chemical shifts increases with the $\mathrm{Al} / \mathrm{Si}$ ratio with a slope in 
agreement with observed values reported in literature. O-Al and O-Si interatomic distances are found to be constant across the calculated compositional range and close to values determined in the extensively investigated calcium aluminosilicate glasses. $\mathrm{Sr}-\mathrm{O}^{[1]}$ and $\mathrm{Sr}-\mathrm{O}^{[2]}$ distances show small variations with the glass composition, despite nearly constant a coordination number ( 7-8) for Sr for both glass series. Such values of the coordination number are close to those observed in crystalline phases formed in transparent polycrystalline ceramics obtained from crystallization of the studied glasses used as precursors. ${ }^{25} \mathrm{MD}$ shows here that the glassy state shares many of the structural features with the crystalline phases which exhibits structural disorder in term of $\mathrm{Al} / \mathrm{Si}$ mixing.

All differences observed between the two potential sets studied, using a Buckingham and Morse for the short-range interactions, can be essentially related to the differences in the predicted $\mathrm{O}^{[\mathrm{n}]}$ populations $(\mathrm{n}=1,2,3)$. Indeed analysis of the strontium coordination number in terms of $\mathrm{O}^{[\mathrm{n}]}$ with a preference factor $\mathrm{P}$ accounting for the $\mathrm{O}^{[\mathrm{n}]}$ population shows that both are equivalent for $\mathrm{O}^{[1]}$ and $\mathrm{O}^{[2]}$, and similar for $\mathrm{O}^{[3]}$. In the same vein, identical $\mathrm{Al} / \mathrm{Si}$ mixing is found with the same kind of analysis. This suggests that the form of the short-range interactions control the $\mathrm{O}^{[\mathrm{n}]}$ populations whereas Coulombic interactions (which are the same for the two models) directly impact other aspects of the structure such as the $\mathrm{Al} / \mathrm{Si}$ mixing and $\mathrm{Sr}-\mathrm{O}^{[\mathrm{n}]}$ contact. As observed for other aluminosilicate glasses, $\mathrm{Si}-\mathrm{O}^{[2]}-\mathrm{Al}$ pairs are favored whereas $\mathrm{Al}-\mathrm{O}^{[1]}$ bond is largely disfavored with respects to $\mathrm{Si}-\mathrm{O}^{[1]}$ ones.

Concerning tricoordinated oxygens $\mathrm{O}^{[3]}$, they are mainly present in small rings, four- (edgesharing) and six-membered, whereas $\mathrm{AlO}_{5}$ dominantly contribute to form edge-sharing configurations. The fact that the two potential sets share these features is indicative that Al$\mathrm{O}^{[3]}$ pairing could be governed by Coulombic interactions, thus ensuring a localized charge 
equilibration at highly constraint points in the glass network. Preliminary analysis of the distribution of these points in large boxes suggest that they are non-homogenously distributed. Detailed analysis of the structure during the quench should shed light on their formation mechanisms.

To confirm our observations, ab-initio molecular dynamics simulations are pursued as well as DFT computation of NMR parameters to further assess our MD models.

\section{Supporting Information}

Derivation of the Sr-O interaction Potentials in the Buckingham form, Figure S1; Fit of the

${ }^{27} \mathrm{AI}$ MAS and MQMAS NMR spectra, Figures S2-S7; 27AI NMR parameters, Tables S1-S2; ${ }^{29} \mathrm{Si}$ NMR parameters, Table S3; Calculations of the total structure factor from MD simulations; Experimental Neutron Structure factors, Figures S8-S9; Variations of bond lengths with glass composition, Figures S10-S11; Variations of Sr-O distances with glass compositions, Figure S12; O-Sr-O angle distributions, Figure S13; O-Si-O bond angle distributions, Figure S14; Variation of TBO / NBO with $\mathrm{AlO}_{5}$, Figure S15; Al/Si Mixing, Figures S16-S18.

\section{Acknowledgements}

This research was conducted under funding from the ANR DyStrAS (Dynamics and Structure of Aluminosilicate glasses) project (ANR-13-BS08-0012).

\section{References}

(1) Allwardt, J. R.; Lee, S. K.; Stebbins, J. F. Bonding Preferences of Non-Bridging O Atoms: Evidence from 0-17 MAS and 3QMAS NMR on Calcium Aluminate and Low-Silica CaAluminosilicate Glasses. Am. Mineral. 2003, 88, 949-954.

(2) Bauchy, M. Structural, Vibrational, and Elastic Properties of a Calcium Aluminosilicate Glass from Molecular Dynamics Simulations: The Role of the Potential. J. Chem. Phys. 2014, 141, 024507. 
(3) Bouhadja, M.; Jakse, N.; Pasturel, A. Structural and Dynamic Properties of Calcium Aluminosilicate Melts: A Molecular Dynamics Study. J. Chem. Phys. 2013, 138, 224510.

(4) Cormier, L.; Ghaleb, D.; Neuville, D. R.; Delaye, J.-M.; Calas, G. Chemical Dependence of Network Topology of Calcium Aluminosilicate Glasses: A Computer Simulation Study. J. Non-Cryst. Solids 2003, 332, 255-270.

(5) Gambuzzi, E.; Pedone, A.; Menziani, M. C.; Angeli, F.; Florian, P.; Charpentier, T. Calcium Environment in Silicate and Aluminosilicate Glasses Probed by 43Ca MQMAS NMR Experiments and MD-GIPAW Calculations. Solid State Nucl. Magn. Reson. 2015, 68-69, 31-36.

(6) Gambuzzi, E.; Pedone, A.; Menziani, M. C.; Angeli, F.; Caurant, D.; Charpentier, T. Probing Silicon and Aluminium Chemical Environments in Silicate and Aluminosilicate Glasses by Solid State NMR Spectroscopy and Accurate First-Principles Calculations. Geochim. Cosmochim. Acta 2014, 125, 170-185.

(7) Ganster, P.; Benoit, M.; Kob, W.; Delaye, J.-M. Structural Properties of a Calcium Aluminosilicate Glass from Molecular-Dynamics Simulations: A Finite Size Effects Study. J. Chem. Phys. 2004, 120, 10172-10181.

(8) Jakse, N.; Bouhadja, M.; Kozaily, J.; Drewitt, J. W. E.; Hennet, L.; Neuville, D. R.; Fischer, H. E.; Cristiglio, V.; Pasturel, A. Interplay between Non-Bridging Oxygen, Triclusters, and Fivefold Al Coordination in Low Silica Content Calcium Aluminosilicate Melts. Appl. Phys. Lett. 2012, 101, 201903.

(9) Moesgaard, M.; Keding, R.; Skibsted, J.; Yue, Y. Evidence of Intermediate-Range Order Heterogeneity in Calcium Aluminosilicate Glasses. Chem. Mater. 2010, 22, 4471-4483.

(10) Neuville, D. R.; Cormier, L.; Massiot, D. Al Coordination and Speciation in Calcium Aluminosilicate Glasses: Effects of Composition Determined by 27Al MQ-MAS NMR and Raman Spectroscopy. Chem. Geol. 2006, 229, 173-185.

(11) Lee, S. K.; Stebbins, J. F. The Degree of Aluminum Avoidance in Aluminosilicate Glasses. Am. Mineral. 1999, 84, 937-945.

(12) Stebbins, J. F.; Dubinsky, E. V.; Kanehashi, K.; Kelsey, K. E. Temperature Effects on Non-Bridging Oxygen and Aluminum Coordination Number in Calcium Aluminosilicate Glasses and Melts. Geochim. Cosmochim. Acta 2008, 72, 910-925.

(13) Stebbins, J. F.; Lee, S. K.; Oglesby, J. V. Al-O-Al Oxygen Sites in Crystalline Aluminates and Aluminosilicate Glasses; High-Resolution Oxygen-17 NMR Results. Am. Mineral. 1999, 84, 983-986.

(14) Stebbins, J. F.; Xu, Z. NMR Evidence for Excess Non-Bridging Oxygen in an Aluminosilicate Glass. Nature 1997, 390, 60-62.

(15) Neuville, D. R.; Cormier, L.; Massiot, D. Al Environment in Tectosilicate and Peraluminous Glasses: A 27AI MQ-MAS NMR, Raman, and XANES Investigation. Geochim. Cosmochim. Acta 2004, 68, 5071-5079.

(16) Skinner, L. B.; Barnes, A. C.; Salmon, P. S.; Fischer, H. E.; Drewitt, J. W. E.; Honkimäki, V. Structure and Triclustering in Ba-Al-O Glass. Phys. Rev. B 2012, 85, 064201.

(17) Stebbins, J. F.; Oglesby, J. V.; Kroeker, S. Oxygen Triclusters in Crystalline CaAl4O7 (Grossite) and in Calcium Aluminosilicate Glasses: O-17 NMR. Am. Mineral. 2001, 86, 1307-1311.

(18) Ganster, P.; Benoit, M.; Delaye, J.-M.; Kob, W. Structural and Vibrational Properties of a Calcium Aluminosilicate Glass: Classical Force-Fields vs. First-Principles. Mol. Simul. 2007, 33, 1093. 
(19) Liu, M.; Jacob, A.; Schmetterer, C.; Masset, P. J.; Hennet, L.; Fischer, H. E.; Jad Kozaily; Jahn, S.; Gray-Weale, A. From Atomic Structure to Excess Entropy: A Neutron Diffraction and Density Functional Theory Study of $\mathrm{CaO}-\mathrm{Al}_{2} \mathrm{O}_{3}-\mathrm{SiO}_{2}$ Melts. J. Phys. Condens. Matter 2016, 28, 135102.

(20) Neuville, D. R.; Cormier, L.; Flank, A.-M.; Briois, V.; Massiot, D. Al Speciation and Ca Environment in Calcium Aluminosilicate Glasses and Crystals by Al and Ca K-Edge XRay Absorption Spectroscopy. Chem. Geol. 2004, 213, 153-163.

(21) Gervais, C.; Profeta, M.; Babonneau, F.; Pickard, C. J.; Mauri, F. Ab Initio Calculations of NMR Parameters of Highly Coordinated Oxygen Sites in Aluminosilicates. J. Phys. Chem. B 2004, 108, 13249-13253.

(22) Pedone, A.; Gambuzzi, E.; Menziani, M. C. Unambiguous Description of the Oxygen Environment in Multicomponent Aluminosilicate Glasses from 170 Solid State NMR Computational Spectroscopy. J. Phys. Chem. C 2012, 116, 14599-14609.

(23) Pedone, A.; Gambuzzi, E.; Malavasi, G.; Menziani, M. C. First-Principles Simulations of the 27Al and 170 Solid-State NMR Spectra of the CaAl2Si3O10 Glass. Theor. Chem. Acc. 2012, 131, 1-11.

(24) Alahraché, S.; Saghir, K. A.; Chenu, S.; Véron, E.; Meneses, D. D. S.; Becerro, A. I.; Ocaña, M.; Moretti, F.; Patton, G.; Dujardin, C.; et al. Perfectly Transparent Sr3Al2O6 Polycrystalline Ceramic Elaborated from Glass Crystallization, Chem. Mater. 2013, 25, 4017-4024.

(25) Saghir, K. A.; Chenu, S.; Veron, E.; Fayon, F.; Suchomel, M.; Genevois, C.; Porcher, F.; Matzen, G.; Massiot, D.; Allix, M. Transparency through Structural Disorder: A New Concept for Innovative Transparent Ceramics, Chem. Mater. 2015, 27, 508-514

(26) Sharma, K.; Kothiyal, G. P.; Montagne, L.; Méar, F. O.; Revel, B. A New Formulation of Barium-strontium Silicate Glasses and Glass-Ceramics for High-Temperature Sealant. Int. J. Hydrog. Energy 2012, 37, 11360-11369.

(27) Hyatt, M. J.; Bansal, N. P. Crystal Growth Kinetics in $\mathrm{BaOAl}_{2} \mathrm{O}_{3} 2 \mathrm{SiO}_{2}$ and $\mathrm{SrOAl}_{2} \mathrm{O}_{3} 2 \mathrm{SiO}_{2}$ Glasses. J. Mater. Sci. 1996, 31, 172-184.

(28) Beall, G. H. Refractory Glass-ceramics Based on Alkaline Earth Aluminosilicates. J. Eur. Ceram. Soc. 2009, 29, 1211-1219.

(29) Cormier, L.; Calas, G.; Creux, S.; Gaskell, P. H.; Bouchet-Fabre, B.; Hannon, A. C. Environment around Strontium in Silicate and Aluminosilicate Glasses. Phys. Rev. $B$ 1999, 59, 13517-13520.

(30) McKeown, D. A.; Kot, W. K.; Pegg, I. L. X-Ray Absorption Studies of the Local Strontium Environments in Borosilicate Waste Glasses. J. Non-Cryst. Solids 2003, 317, 290-300.

(31) Novikov, A. N.; Neuville, D. R.; Hennet, L.; Gueguen, Y.; Thiaudière, D.; Charpentier, T.; Florian, P. Al and Sr Environment in Tectosilicate Glasses and Melts: Viscosity, Raman and NMR Investigation. Chem. Geol. 2017, 461, 115-127.

(32) Park, S. Y.; Lee, S. K. High-Resolution Solid-State NMR Study of the Effect of Composition on Network Connectivity and Structural Disorder in Multi-Component Glasses in the Diopside and Jadeite Join: Implications for Structure of Andesitic Melts. Geochim. Cosmochim. Acta 2014, 147, 26-42.

(33) Stebbins, J. F.; Wu, J.; Thompson, L. M. Interactions between Network Cation Coordination and Non-Bridging Oxygen Abundance in Oxide Glasses and Melts: Insights from NMR Spectroscopy. Chem. Geol. 2013, 346, 34-46. 
(34) Thompson, L. M.; Stebbins, J. F. Non-Stoichiometric Non-Bridging Oxygens and FiveCoordinated Aluminum in Alkaline Earth Aluminosilicate Glasses: Effect of Modifier Cation Size. J. Non-Cryst. Solids 2012, 358, 1783-1789.

(35) Jaworski, A.; Stevensson, B.; Edén, M. The Bearings from Rare-Earth (RE = La, Lu, Sc, Y) Cations on the Oxygen Environments in Aluminosilicate Glasses: A Study by Solid-State 170 NMR, Molecular Dynamics Simulations, and DFT Calculations. J. Phys. Chem. C 2016, 120, 13181-13198.

(36) Jaworski, A.; Stevensson, B.; Edén, M. Direct 170 NMR Experimental Evidence for AlNBO Bonds in Si-Rich and Highly Polymerized Aluminosilicate Glasses. Phys. Chem. Chem. Phys. 2015, 17, 18269-18272.

(37) Hennet, L.; Pozdnyakova, I.; Bytchkov, A.; Cristiglio, V.; Palleau, P.; Fischer, H. E.; Cuello, G. J.; Johnson, M.; Melin, P.; Zanghi, D.; et al. Levitation Apparatus for Neutron Diffraction Investigations on High Temperature Liquids. Rev. Sci. Instrum. 2006, 77, 053903.

(38) Massiot, D.; Touzo, B.; Trumeau, D.; Coutures, J. P.; Virlet, J.; Florian, P.; Grandinetti, P. J. Two-Dimensional Magic-Angle Spinning Isotropic Reconstruction Sequences for Quadrupolar Nuclei. Solid State Nucl. Magn. Reson. 1996, 6, 73-83.

(39) Carr, H. Y.; Purcell, E. M. Effects of Diffusion on Free Precession in Nuclear Magnetic Resonance Experiments. Phys. Rev. 1954, 94, 630-638.

(40) Larsen, F. H.; Farnan, I. 29Si and 170 (Q)CPMG-MAS Solid-State NMR Experiments as an Optimum Approach for Half-Integer Nuclei Having Long T1 Relaxation Times. Chem. Phys. Lett. 2002, 357, 403-408.

(41) Meiboom, S.; Gill, D. Modified Spin-Echo Method for Measuring Nuclear Relaxation Times. Rev. Sci. Instrum. 1958, 29, 688-691.

(42) Fischer, H. E.; Cuello, G. J.; Palleau, P.; Feltin, D.; Barnes, A. C.; Badyal, Y. S.; Simonson, J. M. D4c: A Very High Precision Diffractometer for Disordered Materials. Appl. Phys. A 2002, 74, s160-s162.

(43) Cuello, G. J. Structure Factor Determination of Amorphous Materials by Neutron Diffraction. J. Phys. Condens. Matter 2008, 20, 244109.

(44) A, H. M.; L, M. R.; P , Z. CORRECT: A Correction Program for Neutron Diffraction Data; NFL, Uppsala University, 1996.

(45) Smith, W.; Forester, T. R. DL_POLY_2.0: A General-Purpose Parallel Molecular Dynamics Simulation Package. J. Mol. Graph. 1996, 14, 136-141.

(46) Todorov, I. T.; Smith, W.; Trachenko, K.; Dove, M. T. DL_POLY_3: New Dimensions in Molecular Dynamics Simulations via Massive Parallelism. J. Mater. Chem. 2006, 16, 1911-1918.

(47) Pedone, A.; Malavasi, G.; Menziani, M. C.; Cormack, A. N.; Segre, U. A New SelfConsistent Empirical Interatomic Potential Model for Oxides, Silicates, and Silica-Based Glasses. J. Phys. Chem. B 2006, 110, 11780-11795.

(48) Du, J. Molecular Dynamics Simulations of the Structure and Properties of Low Silica Yttrium Aluminosilicate Glasses. J. Am. Ceram. Soc. 2009, 92, 87-95.

(49) Du, J.; Cormack, A. N. The Structure of Erbium Doped Sodium Silicate Glasses. J. NonCryst. Solids 2005, 351, 2263-2276.

(50) Du, J.; René Corrales, L. Understanding Lanthanum Aluminate Glass Structure by Correlating Molecular Dynamics Simulation Results with Neutron and X-Ray Scattering Data. J. Non-Cryst. Solids 2007, 353, 210-214. 
(51) Okhotnikov, K.; Stevensson, B.; Edén, M. New Interatomic Potential Parameters for Molecular Dynamics Simulations of Rare-Earth (RE = La, Y, Lu, Sc) Aluminosilicate Glass Structures: Exploration of RE3+ Field-Strength Effects. Phys. Chem. Chem. Phys. 2013, 15, 15041-15055.

(52) Florian, P.; Veron, E.; Green, T. F. G.; Yates, J. R.; Massiot, D. Elucidation of the Al/Si Ordering in Gehlenite Ca2Al2SiO7 by Combined 29Si and 27Al NMR Spectroscopy/Quantum Chemical Calculations. Chem. Mater. 2012, 24, 4068-4079.

(53) Duxson, P.; Provis, J. L.; Lukey, G. C.; Separovic, F.; van Deventer, J. S. J. 29Si NMR Study of Structural Ordering in Aluminosilicate Geopolymer Gels. Langmuir 2005, 21, 3028-3036.

(54) Hiet, J.; Deschamps, M.; Pellerin, N.; Fayon, F.; Massiot, D. Probing Chemical Disorder in Glasses Using Silicon-29 NMR Spectral Editing. Phys. Chem. Chem. Phys. 2009, 11, 6935-6940.

(55) Provis, J. L.; Duxson, P.; Lukey, G. C.; van Deventer, J. S. J. Statistical Thermodynamic Model for Si/Al Ordering in Amorphous Aluminosilicates. Chem. Mater. 2005, 17, 2976-2986.

(56) Angeli, F.; Villain, O.; Schuller, S.; Ispas, S.; Charpentier, T. Insight into Sodium Silicate Glass Structural Organization by Multinuclear NMR Combined with First-Principles Calculations. Geochim. Cosmochim. Acta 2011, 75, 2453-2469.

(57) Bernasconi, A.; Dapiaggi, M.; Pavese, A.; Bowron, D. T.; Imberti, S. Local Structure of Si-Al-Ca-Na-O Glasses from Coupled Neutron and X-Ray Total Scattering Data. J. Phys. Chem. B 2012, 116, 13114-13123.

(58) Shimoda, K.; Tobu, Y.; Hatakeyama, M.; Nemoto, T.; Saito, K. Structural Investigation of Mg Local Environments in Silicate Glasses by Ultra-High Field 25Mg 3QMAS NMR Spectroscopy. Am. Mineral. 2007, 92, 695-698.

(59) Xiang, Y.; Du, J.; Smedskjaer, M. M.; Mauro, J. C. Structure and Properties of Sodium Aluminosilicate Glasses from Molecular Dynamics Simulations. J. Chem. Phys. 2013, 139, 044507.

(60) Zheng, Q.; Smedskjaer, M. M.; Youngman, R. E.; Potuzak, M.; Mauro, J. C.; Yue, Y. Influence of Aluminum Speciation on the Stability of Aluminosilicate Glasses against Crystallization. Appl. Phys. Lett. 2012, 101, 041906-041906-4.

(61) Charpentier, T.; Ispas, S.; Profeta, M.; Mauri, F.; Pickard, C. J. First-Principles Calculation of 170, 29Si, and 23Na NMR Spectra of Sodium Silicate Crystals and Glasses. J. Phys. Chem. B 2004, 108, 4147-4161.

(62) Tilocca, A.; de Leeuw, N. H.; Cormack, A. N. Shell-Model Molecular Dynamics Calculations of Modified Silicate Glasses. Phys. Rev. B 2006, 73, 104209.

(63) Benoit, M.; Ispas, S.; Tuckerman, M. E. Structural Properties of Molten Silicates from $\mathrm{Ab}$ Initio Molecular-Dynamics Simulations: Comparison between $\mathrm{CaO}-\mathrm{Al} 2 \mathrm{O} 3-\mathrm{SiO} 2$ and SiO2. Phys. Rev. B 2001, 64, 224205.

(64) Lee, S. K.; Stebbins, J. F. Disorder and the Extent of Polymerization in Calcium Silicate and Aluminosilicate Glasses: 0-17 NMR Results and Quantum Chemical Molecular Orbital Calculations. Geochim. Cosmochim. Acta 2006, 70, 4275-4286.

(65) Bonhomme, C.; Gervais, C.; Folliet, N.; Pourpoint, F.; Coelho Diogo, C.; Lao, J.; Jallot, E.; Lacroix, J.; Nedelec, J.-M.; luga, D.; et al. 87Sr Solid-State NMR as a Structurally Sensitive Tool for the Investigation of Materials: Antiosteoporotic Pharmaceuticals and Bioactive Glasses. J. Am. Chem. Soc. 2012, 134, 12611-12628. 
(66) Xiang, Y.; Du, J. Effect of Strontium Substitution on the Structure of 4555 Bioglasses. Chem. Mater. 2011, 23, 2703-2717.

(67) Jaworski, A.; Stevensson, B.; Pahari, B.; Okhotnikov, K.; Edén, M. Local Structures and $\mathrm{Al} / \mathrm{Si}$ Ordering in Lanthanum Aluminosilicate Glasses Explored by Advanced 27Al NMR Experiments and Molecular Dynamics Simulations. Phys. Chem. Chem. Phys. 2012, 14, 15866-15878.

(68) Stevensson, B.; Jaworski, A.; Edén, M. The Structural Roles of Sc and Y in Aluminosilicate Glasses Probed by Molecular Dynamics Simulations. J. Non-Cryst. Solids 2017, 460, 36-46.

(69) Lee, S. K.; Stebbins, J. F. Al-O-Al and Si-O-Si Sites in Framework Aluminosilicate Glasses with Si/Al=1: Quantification of Framework Disorder. J. Non-Cryst. Solids 2000, 270, 260-264.

(70) Lee, S. K.; Stebbins, J. F. Effects of the Degree of Polymerization on the Structure of Sodium Silicate and Aluminosilicate Glasses and Melts: An 170 NMR Study. Geochim. Cosmochim. Acta 2009, 73, 1109-1119.

(71) Christie, J. K.; Tilocca, A. Aluminosilicate Glasses As Yttrium Vectors for in Situ Radiotherapy: Understanding Composition-Durability Effects through Molecular Dynamics Simulations. Chem. Mater. 2010, 22, 3725-3734. 